\title{
Insights Into Triticum aestivum Seedling Root Rot Caused by Fusarium graminearum
}

\author{
Qing Wang, ${ }^{1}$ Stefanie Vera Buxa, ${ }^{2}$ Alexandra Furch, ${ }^{3}$ Wolfgang Friedt, ${ }^{1}$ and Sven Gottwald ${ }^{1}$ \\ ${ }^{1}$ Department of Plant Breeding, IFZ Research Centre for Biosystems, Land Use and Nutrition, Justus Liebig University, \\ Heinrich-Buff-Ring 26-32, 35392 Giessen, Germany; ${ }^{2}$ Institute of Phytopathology and Applied Zoology, IFZ Research Centre \\ for Biosystems, Land Use and Nutrition, Justus Liebig University, Heinrich-Buff-Ring 26-32, 35392 Giessen, Germany; \\ ${ }^{3}$ Friedrich-Schiller University Jena, Institute of General Botany and Plant Physiology, Dornburger Str. 159, 07743 Jena, Germany
}

Submitted 11 August 2015. Accepted 25 August 2015.

Fusarium graminearum is one of the most common and potent fungal pathogens of wheat (Triticum aestivum), known for causing devastating spike infections and grain yield damage. $F$. graminearum is a typical soil-borne pathogen that builds up during consecutive cereal cropping. Speculation on systemic colonization of cereals by $\boldsymbol{F}$. graminearum root infection have long existed but have not been proven. We have assessed the Fusarium root rot disease macroscopically in a diverse set of 12 wheat genotypes and microscopically in a comparative study of two genotypes with diverging responses. Here, we show a 'new' aspect of the $\boldsymbol{F}$. graminearum life cycle, i.e., the head blight fungus uses a unique root-infection strategy with an initial stage typical for root pathogens and a later stage typical for spike infection. Root colonization negatively affects seedling development and leads to systemic plant invasion by tissueadapted fungal strategies. Another major outcome is the identification of partial resistance to root rot. Disease severity assessments and histological examinations both demonstrated three distinct disease phases that, however, proceeded differently in resistant and susceptible genotypes. Soil-borne inoculum and root infection are considered significant components of the $\boldsymbol{F}$. graminearum life cycle with important implications for the development of new strategies of resistance breeding and disease control.

Fungal pathogens of the genus Fusarium cause two of the globally most important diseases of wheat and other smallgrain cereals, Fusarium head blight (FHB) and Fusarium crown and root rot (FCR and FRR). While FHB has been in the focus of resistance research for many years, soil-borne Fusarium infestations have received less attention (Smiley et al. 2005). Most of our knowledge on Fusarium diseases affecting belowground organs comes from studies on FCR, which is typically attributable to infection of seedling stem bases (leaf sheaths) by $F$. culmorum or $F$. pseudograminearum (Covarelli et al. 2012). Instead, FRR is often understood as a consequence of initial stem-base infection (Knudsen et al. 1995) or contaminated seed (Wang et al. 2006). Brandfass and Karlovsky (2006) reported that speculations on systemic colonization of

Corresponding author: S. Gottwald; Telephone: +49641-9937426; E-mail: sven.gottwald@agrar.uni-giessen.de

*The $\boldsymbol{e}$-Xtra logo stands for "electronic extra" and indicates that eight supplementary figures are published online.

(ㄷ) 2015 The American Phytopathological Society cereal plants via root infections by $F$. culmorum and, possibly, also $F$. graminearum have been revived repeatedly but were not proven at that date. In the meantime, wheat root colonization has been demonstrated in a microscopic analysis for F. culmorum (Beccari et al. 2011). This study confirmed root invasion as a possible basis for further plant colonization, which was supposed to be promoted by the nutrient-rich environment that roots offer to $F$. culmorum. The authors also reported on the rapid development of root necrosis within two days after inoculation, but they did not study the rootinfection process and their observations were solely based on susceptible interactions in the Genio.

In contrast to its relatives F. culmorum or F. pseudograminearum, $F$. graminearum is mainly considered as a paradigm for the floral disease FHB (Trail 2009) and, thus, studies considering $F$. graminearum as a root pathogen are very rare. These studies addressed antagonistic effects of the rhizosphere bacteria Pseudomonas fluorescens on $F$. graminearum-infected barley (Hordeum vulgare) roots (Henkes et al. 2011), the relevance of small-molecular weight root exudates (Lanoue et al. 2010), or the influence of nitrogen applications on root rot severity in wheat seedlings (Rowaished 1981). Although the general competence of $F$. graminearum to colonize wheat roots has been recognized, no microscopic investigation of root infection by $F$. graminearum has been reported (Kazan et al. 2012).

Among Fusarium pathogens, F. graminearum is the main cause of mycotoxin contamination of wheat and, nowadays, shows an unprecedented dissemination even in temperate regions (Magan et al. 2011; Paterson and Lima 2011; Xu and Nicholson 2009). Fusarium toxins such as deoxynivalenol (DON) are a major concern, since they constitute a significant threat to human and animal health (Rocha et al. 2005). There is evidence that FCR causes considerable DON contaminations of wheat stubble and possibly also of spikes (Mudge et al. 2006; Tunali et al. 2012). F. graminearum has been extensively studied as a model for Fusarium pathogens and fungal pathogenicity (Goswami and Kistler 2004). These efforts detected highly diverse genomic regions of pathogenicity-associated genes, which suggest a great adaptability not only to environments or hosts but also during interaction with a single host plant (Cuomo et al. 2007). There are examples of fungal pathogens that are able to adopt different lifestyles, depending on the tissue that is colonized. Magnaporthe grisea, M. oryzae, Colletotrichum graminicola, Leptosphaeria maculans, and Cercospora beticola, traditionally regarded as pathogens of above-ground plant parts, have been reported to infect the roots of their hosts as well (Marcel et al. 2010; Sesma and Osbourn 2004; Sosnowski et al. 2001; Sukno et al. 2008; Vereijssen et al. 
2004). Although root rot is generally regarded as the primary disease caused by soil-borne pathogens (Raaijmakers et al. 2008), the FRR disease pattern and the wheat response are, to our knowledge, still poorly understood, regardless of whether caused by $F$. graminearum or other Fusarium species. However, due to a saprophytic life cycle, Fusarium pathogens are an integral part of the rhizosphere community, with an increasing abundance in regions of intense agriculture (Leplat et al. 2012).

Root functions are indispensable for plant development and, therefore, are often growth- and yield-limiting factors, especially when exposed to soil pathogens (Bennett et al. 2012). The root system is vital for water and nutrient uptake, biosynthesis of important phytohormones (Smith and De Smet 2012), and carbon metabolism regulating the growth of roots and shoots (Kravchenko et al. 2011; Ruan 2014). Infestations by necrotrophic pathogens can cause disintegration of the root structure and functionality, with negative consequences for host nutrient levels, later plant, and yield development as well as to further soil infestations with inoculum (Schneebeli et al. 2015; Walters and Bingham 2007).

The relevance of roots for crop production and sustainable food security has been overseen for a long time (Den Herder et al. 2010). Root diseases are difficult to diagnose, since they proceed unnoticed until they occur in above-ground organs with necrosis on lower stem tissues or typical symptoms mimicking abiotic stress effects, such as drought, nutrient deficiency, stunting, or premature death (Looseley and Newton 2014). Moreover, they are difficult to control, since they can persist for many years and fungicides are not always effective (Raaijmakers et al. 2008). Elite crop varieties with typically low genetic variation have to encounter pathogen populations such as, for example, $F$. graminearum, with a high degree of variability and versatility (Goswami and Kistler 2004; Puri and Zhong 2010). This competition is intensified by the effect of climate change on pathogen prevalence and distribution (Chakraborty and Newton 2011; Esquinas-Alcázar 2005; Looseley and Newton 2014). Therefore, growing resistant wheat cultivars is a central measure to minimize Fusarium damage of the crop. However, resistance breeding essentially depends on resistant germplasm and a better understanding of the disease process. Both are prerequisites for the elucidation of genetic and molecular mechanisms behind pathogen-host interactions, allowing the identification of resistance genes or molecular markers or both. Cultivars with a complete Fusarium resistance are not available, and those carrying partial resistance to FCR (Bovill et al. 2006) or FHB (Rudd et al. 2001) can still suffer yield losses if grown in contaminated fields under favorable environmental conditions.

The present study was undertaken in view of the threat that root infection by soil-borne $F$. graminearum inoculum could pose to wheat production. The objective was to determine whether root infection can be a significant component of the F. graminearum disease cycle by addressing disease severity and the events associated with root infection and colonization of wheat seedlings and whether $F$. graminearum is able to spread into the above-ground plant parts. We found that the head blight pathogen $F$. graminearum employed, for root infection, a unique strategy. This was initially similar to those described for other root-infecting pathogens and a later stage reminiscent of those described for spike infection. Successful root colonization leads to severe necrosis on roots and stem bases, significant decrease of root and shoot development biomass, and further soil infestation by abundant sporulation at the root surface. The fungus spreads from the roots to the aerial plant parts, thereby pursuing different tissue-adapted strategies in stem bases, leaf, and upper stem internodes. The variability observed in the wheat response included genotypes showing partial resistance to FRR. This enabled us to report on unique phenotypic and microscopic insight into a differentially proceeding disease.

\section{RESULTS}

\section{$F R R$ proceeds differently in head blight resistant and susceptible wheat varieties.}

The interaction between $F$. graminearum and wheat seedling roots was characterized in a set of diverse wheat genotypes (Table 1) over a period of 21 days after root inoculation (dai). Supplementary Figures S1 to S3 provide an overview on the severity data of all genotypes (including the significant treatment effects on seedling growth per genotype and timepoint, from analysis of variance [ANOVA] statistics). Inoculations of seedling roots led to $F$. graminearum root colonization by 1 dai, to the formation of necrotic symptoms on roots within 3 dai, as well as on stem bases within 5 to 7 dai. In addition, seedlings challenged with $F$. graminearum showed a decreased root and shoot development. The observed overall mean reduction in root biomass and root and shoot length ranged from 29.6 to $69.4 \%, 10.0$ to $34.4 \%$, and 7.0 to $22.0 \%$, respectively. Images showing the disease impact on roots over time are provided in Supplementary Figure S4.

Table 1. Characteristics of the analyzed wheat genotypes

\begin{tabular}{|c|c|c|c|c|}
\hline Genotype & Origin & Pedigree $^{\mathrm{a}}$ & $\mathbf{F H B}^{\mathbf{b}}$ & Type \\
\hline 'Sumai 3' & China & Funo/Taiwan-Xiaomai; Jingzhou/'Sumai 2' & HR & Spring \\
\hline 'Ning 7840' & China & Avrora/Anhui11(F2)//‘Sumai 3’' & HR & Spring \\
\hline Landrace Wangshuibai & China & LV-CHN; LV-Suyang; LV-Jiangsu & HR & Spring \\
\hline Prebreeding Line 1105.16 & Germany & Hana/Estica & HR & Winter \\
\hline 'Frontana' & Brazil & Fronteira/Mentana & $\mathrm{R}$ & Spring \\
\hline 'Tabasco' & Germany & ZE 90-2666/LW 86Z099-09//CPB 93-27 & MS & Winter \\
\hline Prebreeding Line 1105.13 & Germany & Unknown, origin Romania & MS & Winter \\
\hline Prebreeding Line $172.11^{\mathrm{c}}$ & Germany & Qualibo/ Tommi//Tulsa & MS & Winter \\
\hline ‘Tobak’ & Germany & Ellvis/ Drifter//Koch & $\mathrm{S}$ & Winter \\
\hline 'Remus' & Germany & Famos/Mexican//Sappo & $\mathrm{S}$ & Spring \\
\hline 'Florence-Aurore' & France & Florence/Aurore & HS & Spring \\
\hline 'Line 162.11' & Germany & Tyberius/Opus & HS & Winter \\
\hline
\end{tabular}

a Pedigrees were either obtained from the Wheat Pedigree database (URL below) or were provided by the breeding company W. von Borries Eckendorf GmbH \& Co. KG, Leopoldshöhe, Germany.

${ }^{b}$ Information on the respective responses to Fusarium head blight were obtained from literature (Badea et al. 2008; Buerstmayr et al. 2009) and from breeding company W. von Borries Eckendorf GmbH \& Co. KG. HR = highly resistant, $\mathrm{R}=$ resistant, MS = moderately susceptible, $\mathrm{S}=$ susceptible, HS = highly susceptible.

${ }^{c}$ Since 2014, variety Siegfried in the preregistration for variety approval. 
The results of four genotypes that are exemplary for the observed spectrum of plant-pathogen interactions are shown in Figure 1. Seedlings of Florence-Aurore (Fig. 1A and B) with the lowest level of $F$. graminearum accumulation measured (average level of $0.5 \%$ ) displayed relative minor root necrosis (maximum score 2.5 of 8 ) and minor reduction in the biomass and length of diseased roots (on average 29.6 and 10.0\%). Moreover, for seedlings assessed at 14 and 21 dai, a recovery
A

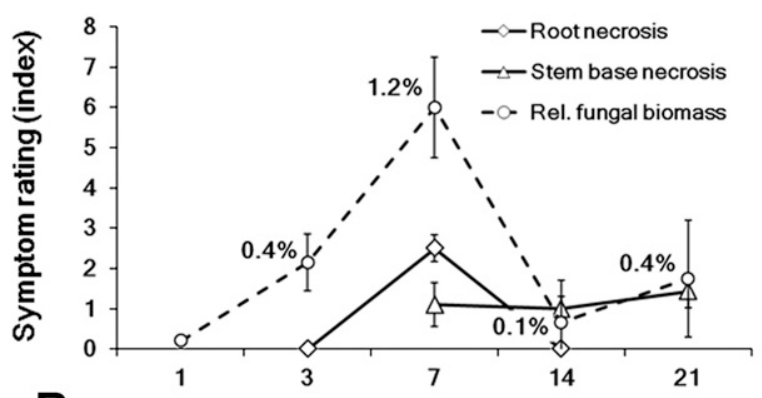

B

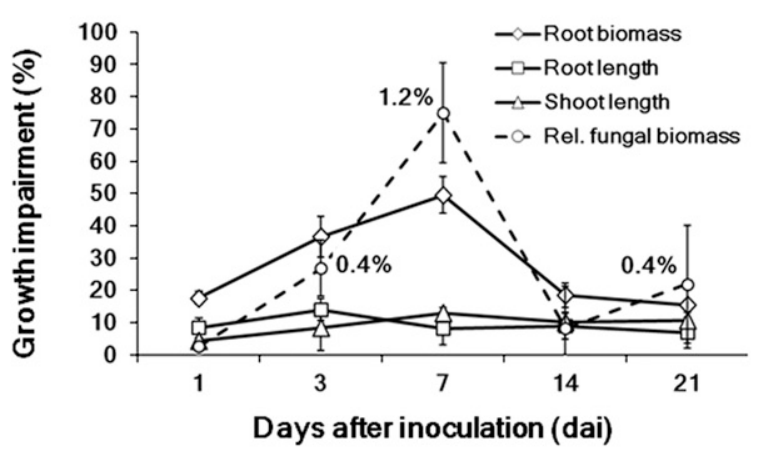

E
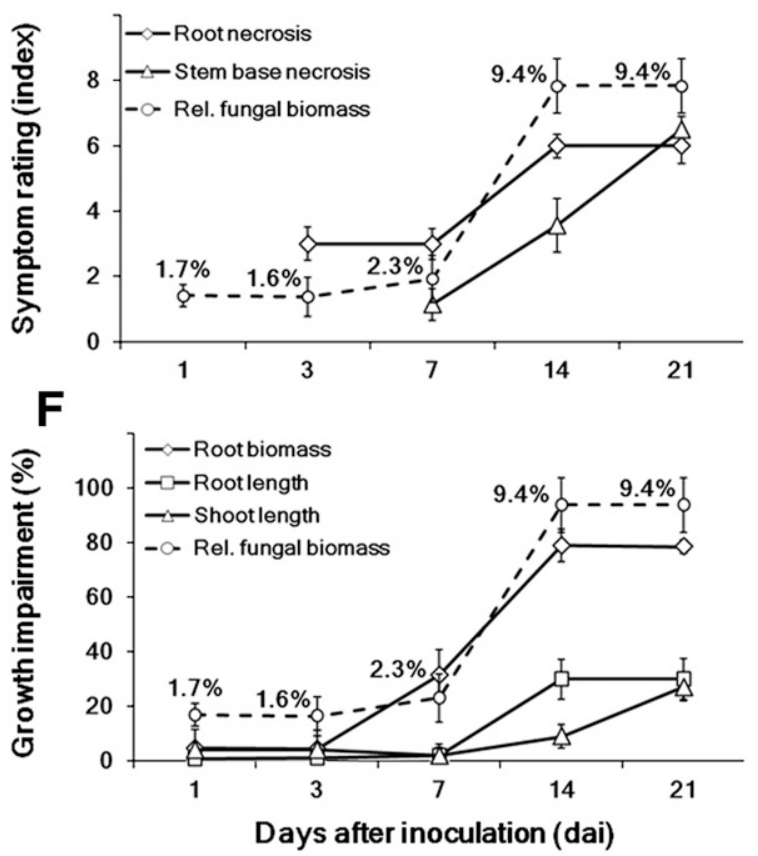

C

cv. Wangshuibai

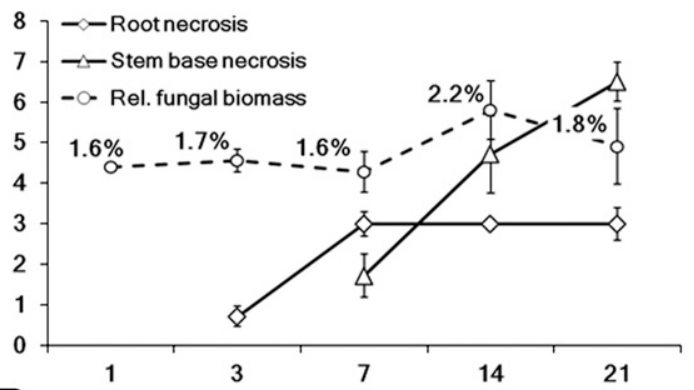

D

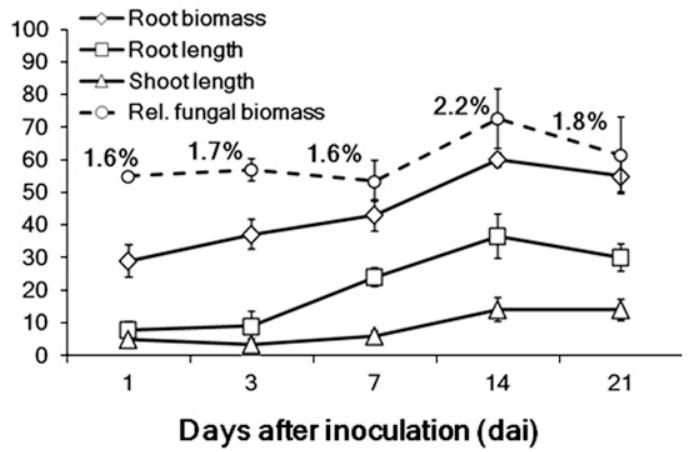

G

Line 1105.16

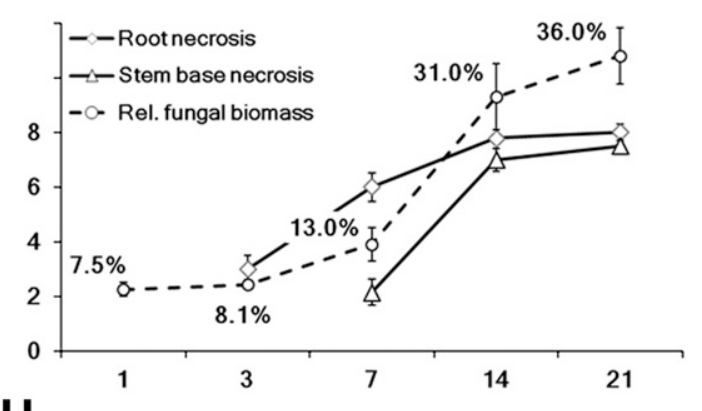

H

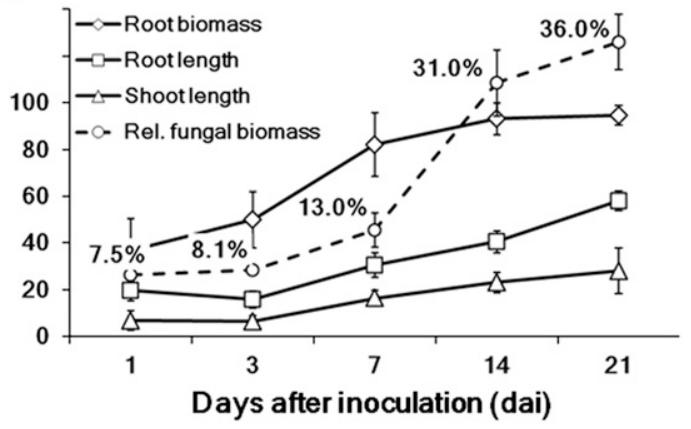

Fig. 1. Mean Fusarium root rot severity in seedlings of the wheat genotypes $\mathbf{A}$ and $\mathbf{B}$, 'Florence-Aurore', $\mathbf{C}$ and $\mathbf{D}$, 'Wangshuibai', $\mathbf{E}$ and $\mathbf{F}$, 'Remus', and $\mathbf{G}$ and H, 'Line 1105.16'. Relative (Rel.) fungal biomass: Fusarium graminearum biomass was measured by reference gene-based real-time quantitative polymerase chain reaction (qPCR) and was calculated as the fungus/wheat root biomass (DNA) ratio. Error bars indicate \pm standard error of the means (S.E.M.) $(n=4$ independent replicates, each, with DNA samples of five seedlings). Symptom rating: Visible symptoms on root and stem bases were rated based on a four-point scale, each for a browning and a symptom extension index: 0 (no symptom) and 8 (severe necrosis on $>75 \%$ of root and crown). Error bars indicate \pm S.E.M. $(n=20)$. Growth impairment: Level of seedling biomass reduction was calculated as percent difference in root biomass (measured by qPCR), root length, and shoot length between inoculated and noninoculated seedlings. Error bars indicate \pm S.E.M. $(n=20$ for root and shoot length; $n=4$ for root biomass, each with DNA samples of five seedlings). 
from the disease could be found, which was verified for all severity assessments (Fig. 1A and B). All these aspects of an impaired FRR progression were, likewise, observed in the genotype 'Line 162.11', which showed an equally low level of root infection (Supplementary Fig. S5A). The relatively moderate fungal accumulation (average level of 1.7\%) that was observed in Wangshuibai (Fig. 1C and D) led to accordingly moderate disease impact on the seedlings, as becomes clear when compared with the impact observed for the genotypes 'Remus' (Fig. 1E and F) and 'Line 1105.16' (Fig. 1G and H). Relatively high root-infection rates as observed for seedlings of genotypes Remus and Line 1105.16 caused necrotic lesions that spread rapidly on root tissues so that, by 21 dai, symptoms were scored 6 (Remus) or even at the maximum of 8 (Line 1105.16). Seedling roots of Line 1105.16 showed the highest measured F. graminearum biomass level (on average 17.5\%), which finally led to a more than $90 \%$ decreased root biomass at 14 and 21 dai (Fig. 1G and $\mathrm{H}$ ). Seedlings of Remus initially responded with a latent period of FRR disease that, by 7 dai, suddenly developed into a period of high severity characterized by an accelerated fungal growth (fourfold) and increased disease impact on the seedling roots (Fig. 1E and F). Such a temporal coordination in the change of $F$. graminearum biomass and symptom expression was also observed for Ning 7840, for which an average fungal biomass load of $8.0 \%$ was measured.

Severe stem-base necrosis and decreases in shoot length were not observed before 7 to 10 dai and typically reached their maximum level at 21 dai (Fig. 1). This observation indicates a progressive disease spread into distal plant parts in consequence of a preceding root colonization by $F$. graminearum. It also demonstrates that the performed root-dip inoculation solely affected the root system. The disease impact on shoots was found to be associated with the preceding level of fungal root colonization. The relative low root infection that was observed for Florence-Aurore led to less severe stem-base necrosis at a maximum of 1.4 (Fig. 1A), while the other three genotypes with relatively moderate and high levels of root infection had maximum scores of 6.5 (Wangshuibai and Remus) and 7.5 (Line 1105.16). Within the entire set of 12 genotypes, only Florence-Aurore and Line 162.11 demonstrated considerably reduced disease impact on the shoots and, thus, an impaired disease spread into the above-ground plant parts.

The repeated measures ANOVA (rANOVA) was applied, which extends ANOVA toward an inference about time effects and time-treatment/genotype interactions on the observed FRR disease phenotypes. Strong, significant treatment and time effects were confirmed by two-way rANOVA (Tables 2 and 3), demonstrating that seedling growth across time proceeded at levels that differed between inoculated and noninoculated plants. Moreover, the significant treatment $\times$ time interactions demonstrated that the progressing disease caused increasing differences in the dynamics of root and shoot growth between healthy and diseased seedlings. These interactions are graphically summarized by the individual mean profile plots of Florence-Aurore and Line 1105.16, which differ clearly in their fungal biomass accumulation and response to FRR (Fig. 2). By considering these mean profile plots, it became evident that, from 3 and 7 dai on, root and shoot growth increasingly diverged between both treatments, due to increasingly lower growth rates of diseased tissues. This was the case for both genotypes. However, inoculated seedlings of Florence-Aurore demonstrated, over the time course, positive trends for root biomass $(63.0$ to $445.5 \mu \mathrm{g})$ and root length $(8.4$ to $30.6 \mathrm{~cm})$ compared with those of Line 1105.16, showing a decreasing

Table 2. Repeated measures analysis of variance (ANOVA) on Fusarium graminearum biomass and root response ${ }^{\mathrm{a}}$

\begin{tabular}{|c|c|c|c|c|c|c|c|c|c|c|c|c|}
\hline & \multicolumn{4}{|c|}{ Relative fungal biomass } & \multicolumn{4}{|c|}{ Root biomass } & \multicolumn{4}{|c|}{ Root length } \\
\hline & df & $\mathbf{F}$ & $\mathbf{P}$ & $\mathbf{E}$ & df & $\mathbf{F}$ & $\mathbf{P}$ & $\mathbf{E}$ & df & $\mathbf{F}$ & $\mathbf{P}$ & $\mathbf{E}$ \\
\hline Treatment ${ }^{\mathrm{b}}$ & - & - & - & - & 1.0 & 330.87 & $<.001$ & 0.88 & 1.0 & 272.86 & $<.001$ & 0.62 \\
\hline Time $^{\mathrm{b}}$ & - & - & - & - & 2.4 & 94.65 & $<.001$ & 0.67 & 3.9 & 589.52 & $<.001$ & 0.78 \\
\hline Treat. $\times$ Time $^{b}$ & - & - & - & - & 3.0 & 69.69 & $<.001$ & 0.60 & 4.2 & 52.07 & $<.001$ & 0.24 \\
\hline Time $^{c}$ & 3.1 & 121.53 & $<.001$ & 0.71 & 5.3 & 98.31 & $<.001$ & 0.73 & 1.3 & 46.54 & $<.001$ & 0.23 \\
\hline Time $\times$ Genot $^{c}$ & 33.7 & 26.00 & $<.001$ & 0.89 & 58.3 & 7.62 & $<.001$ & 0.70 & 65.0 & 5.10 & $<.001$ & 0.26 \\
\hline \multicolumn{13}{|c|}{$\begin{array}{l}\text { all analyses, no sphericity could be assumed }(P<0.05 \text {, Mauchly's test). Results were, therefore, corrected based on the Greenhouse-Geisser } \mathrm{F} \text { test. No } \\
\text { differences were observed in the significance of } \mathrm{F} \text { values between all three corrections, and to 'sphericity-assumed' statistics. df }=\text { degrees of freedom, } \mathrm{F}=\mathrm{F} \\
\text { value, } \mathrm{P}=P \text { value, and } \mathrm{E}=\text { effect size (partial eta squared statistic), which is the strength of associations between main effect or interaction and the dependent } \\
\text { variable. } \\
\text { b Two-way repeated measures ANOVA (rANOVA)on root development in infected and uninfected seedlings, based on two within-subjects factors: time and } \\
\text { treatment. } \\
\text { c Mixed rANOVA on disease progression in terms of fungal growth and decrease of root growth, based on within-subjects factor 'time' and between-subjects } \\
\text { factor 'genotype'. }\end{array}$} \\
\hline
\end{tabular}

Table 3. Repeated measures analysis of variance (rANOVA) on shoot response and symptom development ${ }^{\mathrm{a}}$

\begin{tabular}{|c|c|c|c|c|c|c|c|c|c|c|c|c|}
\hline & \multicolumn{4}{|c|}{ Shoot length } & \multicolumn{4}{|c|}{ Root necrosis } & \multicolumn{4}{|c|}{ Stem base necrosis } \\
\hline & df & $\mathbf{F}$ & $\mathbf{P}$ & $\mathbf{E}$ & df & $\mathbf{F}$ & $\mathbf{P}$ & $\mathbf{E}$ & df & $\mathbf{F}$ & $\mathbf{P}$ & $\mathbf{E}$ \\
\hline Treatment $^{\mathrm{b}}$ & 1 & 240.72 & $<.001$ & 0.59 & - & - & - & - & - & - & - & - \\
\hline Time $^{\mathrm{b}}$ & 3.1 & 989.49 & $<.001$ & 0.86 & - & - & - & - & - & - & - & - \\
\hline Treat. $\times$ Time $^{b}$ & 3.9 & 42.41 & $<.001$ & 0.20 & - & - & - & - & - & - & - & - \\
\hline Time $^{\mathrm{c}}$ & 5.5 & 20.73 & $<.001$ & 0.12 & 4.3 & 611.99 & $<.001$ & 0.80 & 3.6 & 348.41 & $<.001$ & 0.69 \\
\hline Time $\times$ Genot $^{c}$ & 60.8 & 2.81 & $<.001$ & 0.17 & 46.9 & 44.01 & $<.001$ & 0.76 & 39.9 & 14.25 & $<.001$ & 0.50 \\
\hline
\end{tabular}

a In all analyses no sphericity could be assumed $(P<0.05$, Mauchly's test); results were therefore corrected based on the Greenhouse-Geisser $\mathrm{F}$ test. No differences were observed in the significance of $\mathrm{F}$ values between all three corrections, and to 'sphericity-assumed' statistics. df $=$ degrees of freedom, $\mathrm{F}=\mathrm{F}$ value, $\mathrm{P}=P$ value, and $\mathrm{E}=$ effect size (partial eta squared statistic), which is the strength of associations between main effect or interaction and the dependent variable.

b Two-way rANOVA on shoot development in infected and uninfected seedlings, based on two within-subjects factors, time and treatment.

${ }^{c}$ Mixed rANOVA on disease progression in terms of decrease of shoot growth and necrosis development on roots and stem bases, based on the within-subjects factor 'time' and the between-subjects factor 'genotype'. 
trend for root biomass (50.8 to $16.5 \mu \mathrm{g}$ ) and an almost neutral trend for root length $(10.0$ to $16.2 \mathrm{~cm})$. Concerning the shoot growth, both genotypes showed an average decrease of $5.3 \%$ between 0.5 and 5 dai, while between 7 and 21 dai, the shoot decreased, on average, by $13.3 \%$ for Florence-Aurore and by $22.8 \%$ for Line 1105.16 .

This was the case for both genotypes. However, over the time course, inoculated seedlings of Florence-Aurore demonstrated positive trends for root biomass (63.0 to $445.5 \mu \mathrm{g}$ ) and root length $(8.4$ to $30.6 \mathrm{~cm}$ ) compared with those of Line 1105.16 showing a decreasing trend for root biomass (50.8 to $16.5 \mu \mathrm{g}$ ) and an almost neutral trend for root length $(10.0$ to $16.2 \mathrm{~cm})$. Concerning shoot growth, both genotypes showed an average decrease of $5.3 \%$ between 0.5 and 5 dai, while between 7 and
21 dai, the shoot decreased, on average, by $13.3 \%$ for FlorenceAurore and by $22.8 \%$ for Line 1105.16 . A comparatively low FRR impact on seedling development together with a positive growth trend under disease conditions was also observed for Line 162.11, with an impaired fungal growth (on average $0.5 \%$ ) equal to Florence-Aurore. The mean profile plot of Line 162.11 is shown in Supplementary Figure S6 together with the plot of Ning 7840, with a disease response similar to Line 1105.16. Finally, the mean plots illustrate the major observation that the loss of root biomass was the most severe impact to wheat seedlings caused by FRR. This generally also applied to Florence-Aurore and Line 162.11 but with the important difference that these impacts were substantially lower compared with the other genotypes tested.

\section{cv. Florence-Aurore}

A

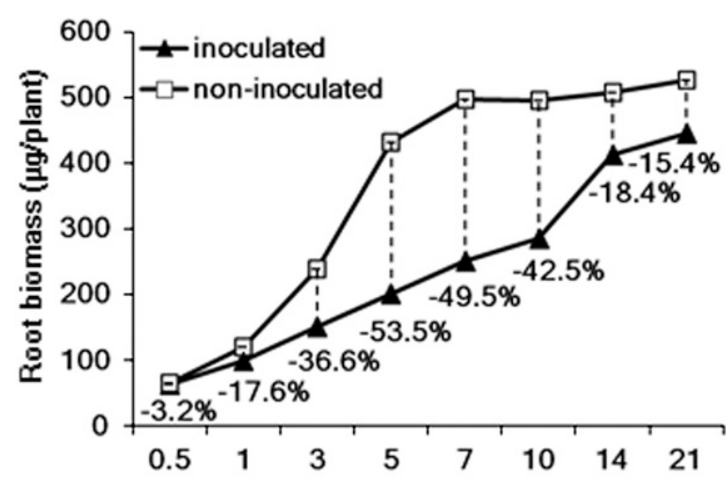

B

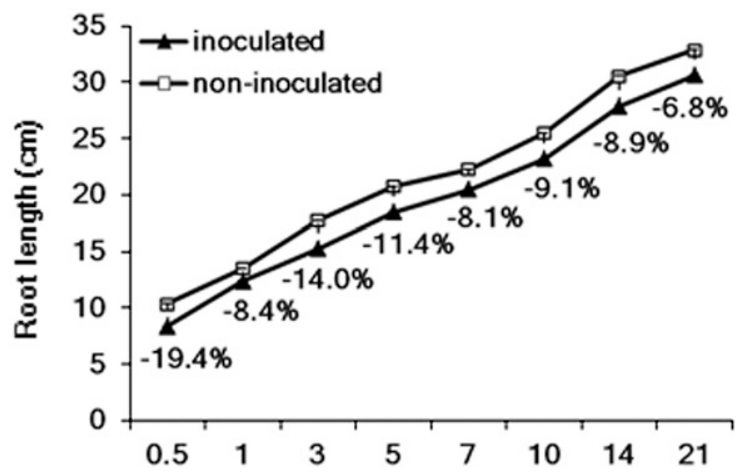

C

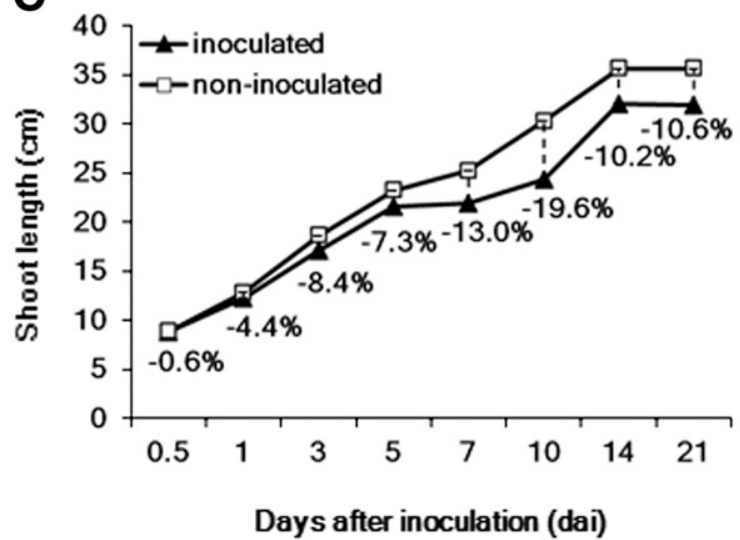

Line 1105.16

D

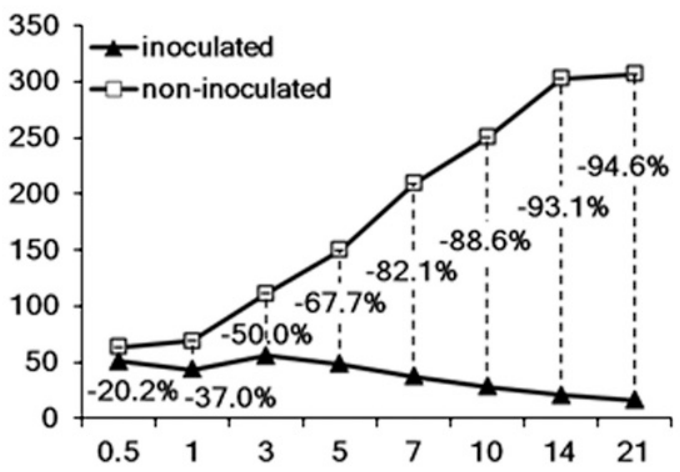

E

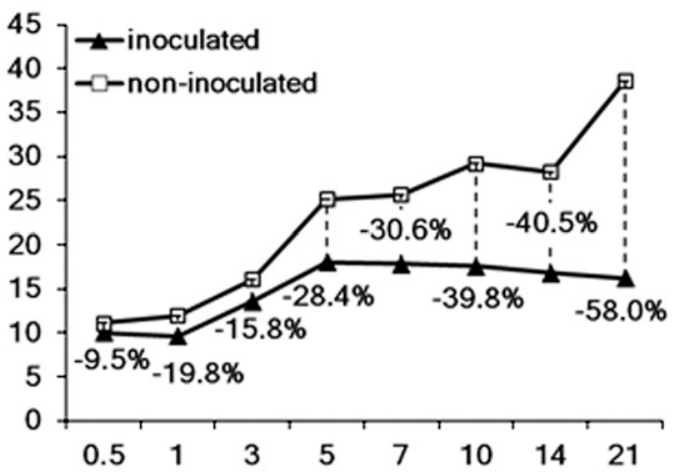

$\mathbf{F}$

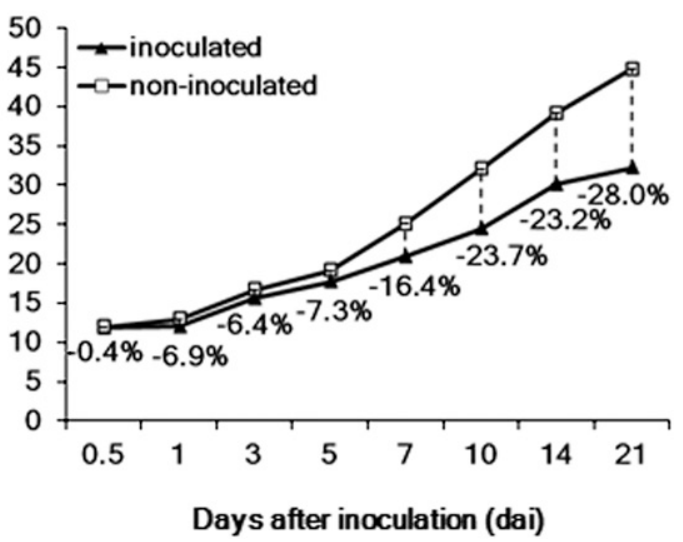

Fig. 2. Developmental responses of wheat seedlings to Fusarium root rot caused by Fusarium graminearum. A to C, Mean profile plot of Florence-Aurore with reduction levels in root biomass, root, and shoot length observed for inoculated seedlings. D to F, Mean profile plot of Line 1105.16 with reduction levels in root biomass, root, and shoot length observed for inoculated seedlings. Developmental responses over time were assessed as percent change in root biomass, root length, and shoot length between inoculated and noninoculated seedlings (each $n=20$ seedlings). 
Since both the single timepoint estimates and the rANOVA on seedling biomass loss indicated dynamic plant-pathogen interactions, a mixed rANOVA was applied on the general FRR progression in terms of fungal growth, reduction in seedling biomass, and visible symptoms. This analysis verified the progressive nature of FRR, because significant effects of time were attested for all six severity traits (Tables 2 and 3). For the fungal development, the Bonferroni adjusted posthoc pairwise comparisons demonstrated that $F$. graminearum generally proceeded in three distinct phases. Significant changes in general (mean quantities) fungal growth were found between 1 and 3 dai $(P=0.018)$ and 7 and 10 dai $(P=0.004)$. The rANOVA indicated that the second phase (3 to 7 dai) in fungal growth is most critical for disease establishment. This phase was generally characterized by an accelerated fungal growth that coincided with symptom induction on roots at about 3 dai (Fig. 1) and with an increasing divergence in diseased and healthy seedling growth (Fig. 2). The third phase was additionally associated with increasing impact on shoots in terms of a length reduction and a formation of necrotic symptoms (Fig. 1 and 2). Moreover, as summarized in Table 4 and demonstrated in the context of microscopic studies (below), each of the three phases was characterized by specific fungal processes and events in the $F$. graminearum-wheat root interaction.

Besides the pathogen, the genotype significantly determines the level of disease symptom expression because significant time $\times$ genotype interactions were confirmed for all six severity traits by rANOVA (Tables 2 and 3 ). For $F$. graminearum accumulation, pairwise comparisons suggested a genotypic variation in which genotypes Florence-Aurore and Line 162.11 (minimum $F$. graminearum accumulation) and genotypes Tobak, Ning 7840, and Line 1105.16 (maximum $F$. graminearum accumulation) were clearly separated from the remaining seven genotypes $(P=0.005$ and $P<0.0001$, respectively). The genotype rankings in Figure 3 provide an overview on the range of seedling responses that were observed in this study. The ranking presented in Figure $3 \mathrm{~A}$ illustrates mean relative fungal biomass quantities that were distributed over a range of 0.5 (Florence-Aurore and Line 162.11) to $17.3 \%$ (Line 1105.16). In addition, to evaluate the genotypic performances under disease conditions, a FRR disease index (FDI) was calculated, including all six severity parameters that were assessed in this study (Fig. 3B). The respective FDI scores were ranked in an ascending order in which a lower FDI is considered equal to higher levels of resistance while a higher FDI is considered equal to a higher susceptibility. In both rankings, genotypes FlorenceAurore and Line 162.11 demonstrated a (partial) resistance to FRR. Different levels of susceptibility from moderate (e.g., Tabasco and Wangshuibai) to high (Tobak and Ning 7840 and Line 1105.16) could be defined for the other 10 genotypes.
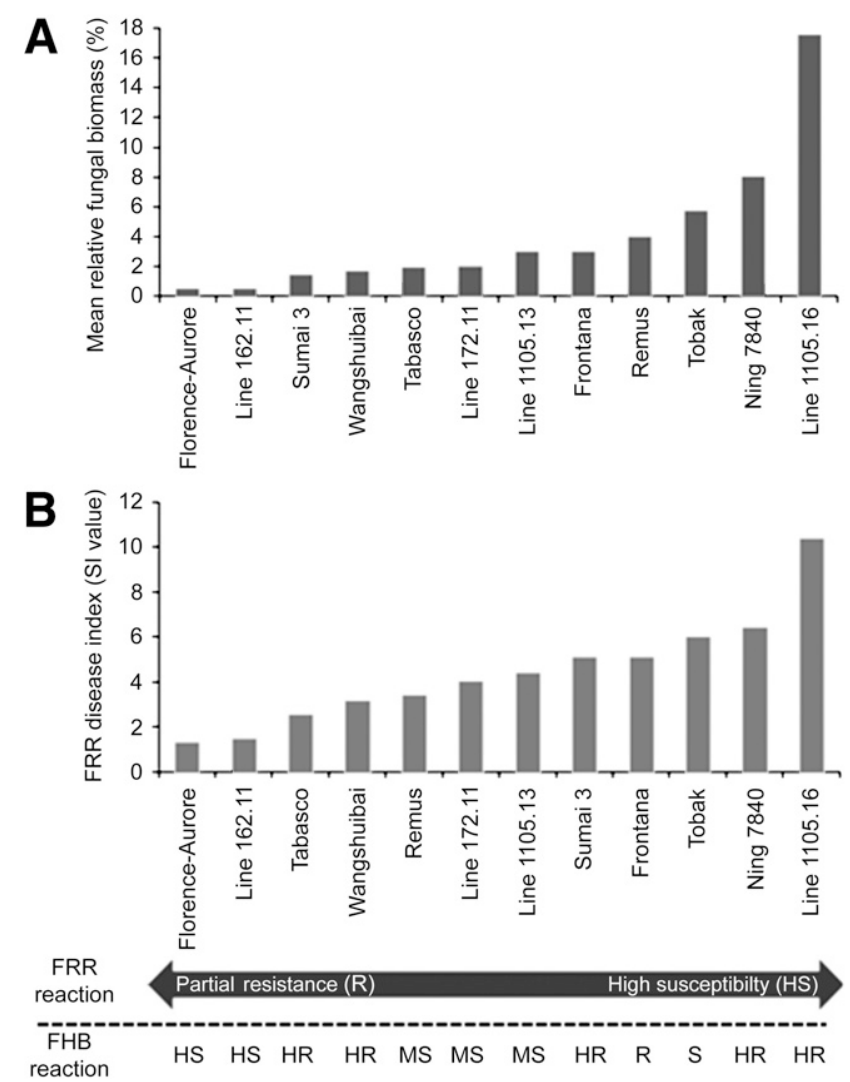

Fig. 3. Variation in the response to Fusarium root rot observed among 12 wheat genotypes. A, Genotypes ranked according to relative fungal biomass in roots, mean levels over eight measurement timepoints. B, Genotypes ranked according to the Fusarium root rot disease index (FDI), mean FDI over eight measurement timepoints. FDI scores are ranked in an ascending order, in which a lower FDI is considered equal to higher relative resistance, while a higher FDI is considered equal to a higher relative susceptibility. For all genotypes, the reactions to Fusarium head blight are listed. HR = highly resistant, $\mathrm{R}=$ resistant, $\mathrm{MS}$ = moderately susceptible, $\mathrm{S}=$ susceptible, HS = highly susceptible.

Table 4. Three phases in the course of Fusarium root rot as observed by severity assessments with five main events as observed by microscopy ${ }^{\mathrm{a}}$

\begin{tabular}{|c|c|c|c|c|c|c|c|}
\hline \multirow{3}{*}{$\frac{\text { Disease stage }}{\text { Main event }}$} & \multirow{3}{*}{$\begin{array}{c}\text { Phase I } \\
0.5 \text { to } 1.0 \text { dai } \\
\text { Early infection } \\
\text { Surface colonization }\end{array}$} & \multicolumn{3}{|c|}{$\begin{array}{l}\text { Phase II } \\
3 \text { to } 7 \text { dai }\end{array}$} & \multicolumn{3}{|c|}{$\begin{array}{l}\text { Phase III } \\
10 \text { to } 21 \text { dai }\end{array}$} \\
\hline & & \multirow{2}{*}{$\frac{\text { Main infection }}{\text { Penetration }}$} & \multicolumn{2}{|c|}{ Root colonization } & \multicolumn{3}{|c|}{ Spread into above-ground plant parts } \\
\hline & & & Sporulation & Cortex invasion & Stem base & Leaf blade & Stem apex \\
\hline Typical fungal morphology & $\begin{array}{l}\text { Net mycelium } \\
\text { Simple infection hyphae }\end{array}$ & $\begin{array}{l}\text { Runner hyphae } \\
\text { Foot structures } \\
\text { Infection cushions }\end{array}$ & $\begin{array}{l}\text { Sporodochia } \\
\text { Macroconidia } \\
\text { Chlamydospores }\end{array}$ & & & & \\
\hline Necrosis & No & Yes & Yes & Yes & Yes & No & No \\
\hline DON detection ${ }^{\mathrm{b}}$ & Not possible & Not possible & Not possible & Yes & Yes & Yes & Yes \\
\hline Susceptibility & 0.5 to 1 dai & 3 dai & 5 dai & 7 dai & 10 dai & 14 dai & 25 dai \\
\hline Sections colonized & & & & $45 / 45$ & $45 / 45$ & $45 / 45$ & $45 / 45$ \\
\hline $\begin{array}{l}\text { Resistance } \\
\text { Sections colonized }\end{array}$ & 0.5 to 1 dai & 3 dai & 5 dai & $\begin{array}{l}21 \text { dai } \\
40 / 45\end{array}$ & $\begin{array}{l}21 \text { dai } \\
45 / 45\end{array}$ & $\begin{array}{l}28 \text { dai } \\
23 / 45\end{array}$ & $\begin{array}{l}28 \text { dai } \\
22 / 45\end{array}$ \\
\hline Disease nhases I to JU & & & & & & & \\
\hline $\begin{array}{l}\text { Disease phases } 1 \text { to } \\
\text { Observations were made a } \\
\text { Florence-Aurore. For each } \\
\text { Timepoints refer to initial } \\
\text { 'section colonized' refers t } \\
\text { inoculation. }\end{array}$ & $\begin{array}{l}\text { to significant changes } 1 \\
\text { seedling roots, stem bases } \\
\text { seedling, tissue in a total } \\
\text { bservations and make no } \\
\text { considerably invaded tiss }\end{array}$ & $\begin{array}{l}\text { leaf blades, and upp } \\
5 \text { of cross sections g } \\
\text { laim to the actual be } \\
\text { es, while tissues inve }\end{array}$ & $\begin{array}{l}\text { lnearum growth su } \\
\text { er stem internodes } \\
\text { enerated in three in } \\
\text { ginning or ending c } \\
\text { aded by only few hy }\end{array}$ & $\begin{array}{l}\text { d susceptible pret } \\
\text { dependent root in } \\
\text { f a certain disease } \\
\text { phae were not cor }\end{array}$ & $\begin{array}{l}\text { measure an } \\
\text { eding Line } \\
\text { ulations wer } \\
\text { tage. For co } \\
\text { dered for th }\end{array}$ & $\begin{array}{l}05.16 \text { and pa } \\
\text { microscopic } \\
\text { parison purp } \\
\text { table. dai }=\mathrm{c}\end{array}$ & $\begin{array}{l}\text { tial resistant } \\
\text { ly analyzed. } \\
\text { ses, the term } \\
\text { ys after root }\end{array}$ \\
\hline
\end{tabular}


A noticeable deviation in the ranking positions was particularly obtained for 'Sumai 3'. Despite a moderate infection level (average $1.4 \%$ ) (Fig. 3A), inoculated seedlings of this cultivar demonstrated levels of necrosis (average rates of 5 and 4 for roots and stem bases, respectively) and developmental impact (average reduction of diseased root biomass, root, and shoot length 69.0, 38.0, and $21.7 \%$, respectively) that were only marginally better than those observed in highly susceptible Line 1105.16 (Fig. 1G and $\mathrm{H})$. Finally, the genotype ranking also demonstrates that resistance against FHB is not functional against FRR. The FHB-susceptible genotypes Florence-Aurore and Line 162.11 were much less affected by root rot than the genotypes Sumai 3, Ning 7840, and Wangshuibai, all expressing pronounced FHB resistances.

\section{F. graminearum uses defined developmental processes for root infection.}

For all 12 wheat genotypes, quantitative PCR (qPCR) proved successful root infection (Fig. 1), demonstrating absence of a seedling resistance to root infection and greater ability of the FHB pathogen to penetrate roots. To uncover the processes enabling
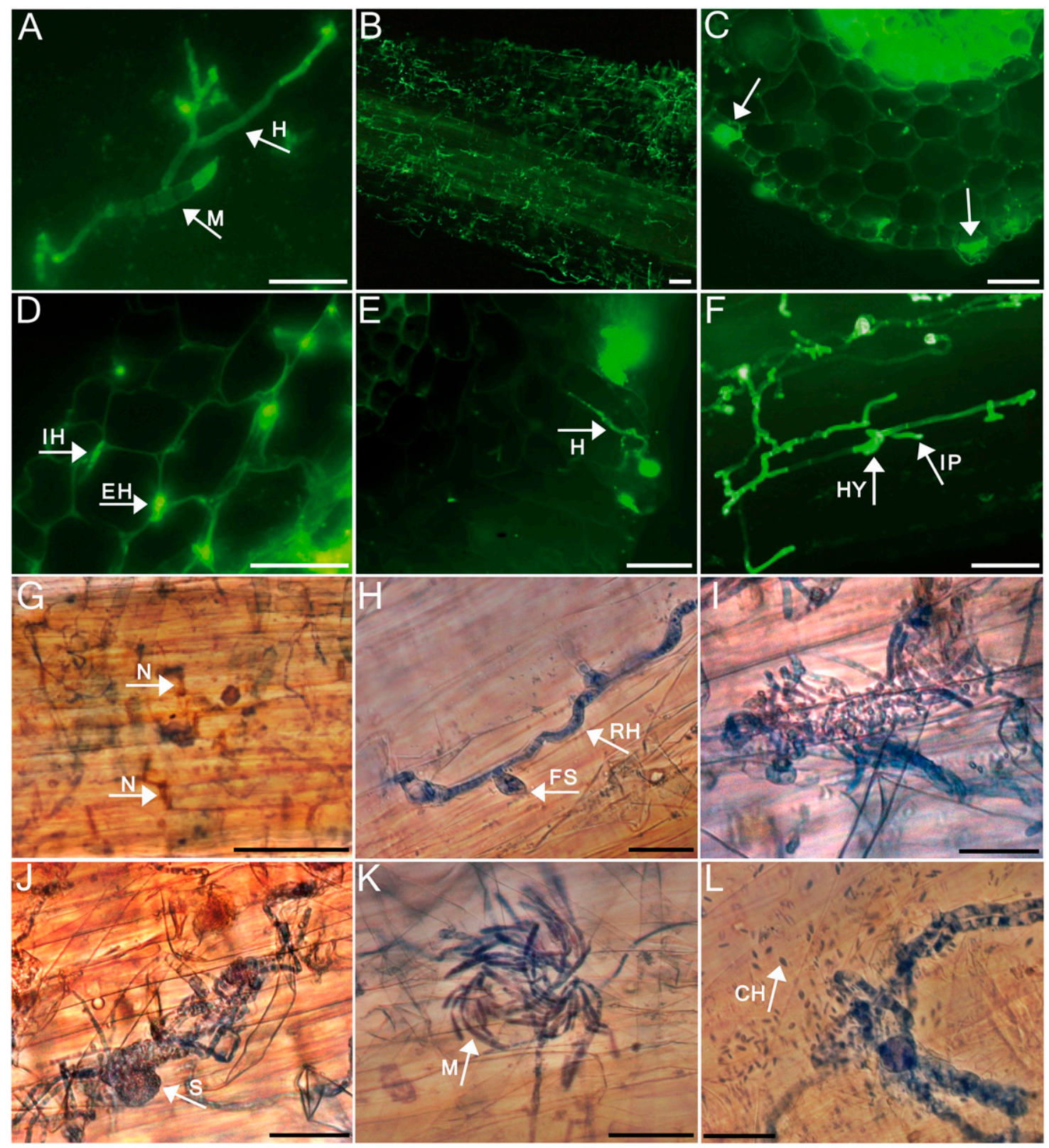

Fig. 4. Infection of wheat seedling roots by Fusarium graminearum isolate IFA 65. A to F, During early infection, F. graminearum undergoes developmental processes typical for root-infecting fungi. A, Germinating macroconidia bearing hyphae on the root surface of Florence-Aurore at 0.5 days after root inoculation (dai). B, Hyphae network developed on the root surface of 'Line 1105.16' at 1 dai. C, Epidermis cells of Florence-Aurore roots colonized by F. graminearum hyphae at 1 dai (white arrows). D, Intra- and extracellular hyphae in the root cortex of Line 1105.16 at 1 dai. E, Hyphae entering cortex cells of Line 1105.16 at 1 dai (white arrow). F, Penetration peg developed from hyphal swelling in the net-forming mycelium (hyphopodia) on root surface of Line 1105.16 at 1 dai. Images were obtained by fluorescence microscopy on WGA Alexa Fluor 488-stained fungal structures. G to L, During main infection and sporulation, F. graminearum undergoes developmental processes reminiscent of floret infections. G, Necrotic root cells on the root surface of Line 1105.16 at 3 dai (white arrows). H, Foot structure branching from runner hyphae on the root surface of Florence-Aurore at 3 dai. I, Coral-like hyphal mats (infection cushion) on the root surface of Line 1105.16 at 3 dai. J, Sporodochia within infection cushion on the root surface of Line 1105.16 at 5 dai. K, Macroconidia on the root surface of Line 1105.16 at 5 dai. $\mathbf{L}$, Chlamydospores on the root surface of Florence-Aurore at 5 dai. Images were obtained by bright-field microscopy on trypan blue-stained fungal structures. $\mathrm{CH}=$ chlamydospores, $\mathrm{EH}=$ extracellular hyphae, $\mathrm{FS}=$ foot structures, $\mathrm{H}=$ hyphae, $\mathrm{HY}=$ hyphopodia, $\mathrm{IC}=$ infection cushion, $\mathrm{IH}$ intercellular hyphae, $\mathrm{IP}=$ infection peg, $\mathrm{M}=$ macroconidia, $\mathrm{RH}=$ runner hyphae, and $\mathrm{S}=$ sporodochia. Bars: $25 \mu \mathrm{m}$. 
F. graminearum to infect wheat roots, microscopic investigations were conducted in an experiment covering the period from 0.5 to 5 dai. F. graminearum was found to undergo defined events of hyphae proliferation and differentiation on the roots of Florence-Aurore and Line 1105.16, which comprises early infection, main infection, and sporulation (Table 4). Briefly, F. graminearum was generally able to develop the same infection structures on resistant and susceptible roots and, thus, differences between both genotypes became only verifiable with the hyphal migration into the root cortex.

At 0.5 dai, macroconidia germinated (Fig. 4A), producing fungal hyphae that rapidly formed dense networks on the root surfaces (Fig. 4B). At 1 dai, hyphae networks covering the entire longitudinal axis up to the root-cap regions were observed for Line 1105.16 but not for Florence-Aurore. Hyphae networks on roots of Florence-Aurore were comparatively less distributed. At 1 dai, first penetrations of root epidermis were observed at infection sites. For Line 1105.16, sporadic hyphal migrations into cortex cells were already found (Fig. 4C and D), complying with the early qPCR detections of fungal biomass (Fig, 1). Hyphae were found to spread from epidermal cells to cortical parenchyma cells (Fig. 4E). Simultaneously, hyphal structures morphologically distinct from the network-forming vegetative mycelium were observed (Fig. 4F), reminiscent of simple infection structures (hyphopodia) appearing as swollen hyphae, which generated penetration pegs invading the root epidermis. Pathogen establishment and early infection progressed without symptoms.

The rANOVA and time-course data suggested a change in the disease progression at 3 dai (Table 4), leading to a phase of increased disease intensity. This change was found to be associated with formation of more complex infection structures by $F$. graminearum. At 3 dai, the infection process was characterized by first necrotic root cells (Fig. 4G), runner hyphae that branched to form foot structures (Fig. 4H), and infection cushions appearing as coral-like hyphal mats (Fig. 4I). These specialized structures, together with the measured increases in fungal biomass, demonstrated the establishment of the main infection stage. Finally, root infections occurred by physical contact of roots with mycelium, which originated from spores and developed infection structures. The third stage was characterized by an enhanced sporulation. From 5 dai on sporodochia (Fig. 4J), macroconidia (Fig. 4K) and chlamydospores (Fig. 4L) had developed.

\section{Root and stem-base colonization proceeds differently in root rot-resistant and-susceptible wheat varieties.}

Confocal laser scanning microscopy was conducted in three independent inoculation experiments to investigate the unknown systemic growth of $F$. graminearum in the wheat roots and in above-ground plant parts in the period 7 to 28 dai. Generally, for noninoculated control plants, neither symptoms nor any fungal hyphae were detected (Fig. 5A and B). The analyzed plants were free from contaminations by other plant-colonizing fungi and the presence of $F$. graminearum was confirmed by reisolation on agar as described below. Subsequent to the root-infection process, at 7 dai, fungal invasion in seminal roots of highly susceptible Line 1105.16 was demonstrated by extra- and intercellular hyphae colonizing the cortex cells (Fig. 5C and D). This demonstrated that FRR had developed into the main root colonization stage (Table 4). Massive cortex colonization was also observed in root sections collected at timepoints 10, 14, 21, and 28 dai, regardless of whether sections were obtained from necrotic or symptom-free root areas.

The stage of root penetration with hyphae in front and within the epidermis is shown based on a root section obtained from Florence-Aurore at 7 dai (Fig. 5E). The invasion of FlorenceAurore roots was stopped at the epidermis cells, a situation that was maintained until the timepoint 21 dai, at which a first invasion of the inner root layer by a few hyphae was detectable (Supplementary Fig. S7). Thus, resistance to root rot in the first instance is characterized by an extension of the time required by the pathogen to colonize the root cortex. This explains results from the qPCR quantifications of fungal biomass that demonstrated an almost unchanged, low fungal growth over time for Florence-Aurore (Fig. 1A and B), accompanied by reduced root necrosis. Hyphae invading the endodermis, phloem, and xylem were not observed in either wheat genotype. Besides, in both microscopic studies, we have not observed hyphae in root-hair cells.

To investigate the systemic fungal spread into noninoculated plant organs, the seedling stem base was divided into three segments (S1 to S3), plus the stem apex (SA), as shown in the sketch of a wheat seedling in Figure 5. With the invasion of stem bases, the pathogen changed its strategy. Now, it colonized the parenchyma cells but, also, the entire vascular tissue. Figure $5 \mathrm{~F}$ shows a vascular bundle of segment S2 at 14 dai demonstrating the presence of $F$. graminearum in the sclerenchyma, phloem, and xylem cells of susceptible Line 1105.16. Moreover, hyphae were found in the pith parenchyma and also in the bundle sheath surrounding the vascular bundles (Fig. 5F and Q). In susceptible seedlings, the outer two leaf sheaths (L1 and L2) of stem segment S1 were already colonized at 7 dai, and at 10 and 14 dai, hyphae had also invaded the inner leaf sheath L3 (Fig. 5G). Thus, in the case of a susceptible interaction, FRR reached the stage of a vertical spread at 7 to 10 dai (Table 4). A fungal migration into the next higher segment (S2) was observed at 14 dai, while at 25 dai, parenchyma and vascular bundles of segments S3 and SA were invaded, as shown for a leaf crown of Line 1105.16 (Fig. 5N and O).

At 14 dai, segments S1 and S2 of Florence-Aurore consisted of a central culm enwrapped by two leaf sheaths (L1, L2). At this timepoint, all cross sections of stem-base segments S1, S2 (Fig. 5H and I), and S3 showed vascular bundles that were surrounded by green fluorescence signals that were observed in neither Line 1105.16 nor in uninfected sections. A signal separation from individual channels of laser scanning microscope demonstrated that these signals radiate from the cells of the bundle sheath rather than from fungal hyphae. Interestingly, although the root cortex was noncolonized at 10 dai, a few cross sections of S1 (eight of 45) showed first hyphae that were, however, restricted to the periphery of L1 and were absent from vascular bundles. This situation did not significantly change until 21 dai, when all examined cross sections showed hyphae in L1 and L2, while the central stem and vascular bundles were only sporadically invaded (Fig. 5I). Generally, the fungal migration into stem base was significantly weaker in Florence-Aurore as compared with Line 1105.16 and mainly concerned stem bases obtained from necrotic areas.

\section{Colonization of stem and leaf blades proceeds undifferentiated in root rot resistant and susceptible wheat varieties.}

Once $F$. graminearum had entered the upper stem (SA) tissues, the colonization was found to proceed undifferentiated between both genotypes. At 28 dai, parenchyma and vascular tissue of about half of the examined SA sections obtained from Florence-Aurore (Table 4) were entirely colonized (Fig. 5P and Q), as was observed for Line 1105.16 by 25 dai (Fig. $5 \mathrm{~N}$ and $\mathrm{O}$ ). Even heavy fungal invasions into the upper stem internode were not associated with visible necrosis formation, neither for Line 1105.16 nor for Florence-Aurore.

From 10 dai on, $F$. graminearum had invaded the leaf blades of Line 1105.16 (Fig. 5J and K), and from 14 dai on, leaf blade 
invasions were also observed for Florence-Aurore (Fig. 5L and M). However, while hyphae were found in all investigated leaf blades of Line 1105.16, half the leaves of Florence-Aurore were healthy until 28 dai, the final examination timepoint (Table 4). As found for the upper stem internode, the leaf colonization was, for both wheat genotypes, symptomless. Hyphae were exclusively observed in cells beneath or in the trichomes and, to a lower extent, in the substomatal chambers. While trichomes were the preferential targets for $F$. graminearum invasion, hyphae have not been observed in the vascular bundles or in the mesophyll cells of leaves.

As microscopically demonstrated, seedling root colonization can be the gateway for further systemic disease spread into distal plant parts during postseedling stages. This possibility was additionally investigated by locating the pathogen (qPCR based) and the DON toxin (enzyme-linked immunosorbent assay [ELISA] based) at the wheat growth-stages seedling (Z13), tillering (Z21-22), stem elongation (Z32), and late flowering (Z64-68). For this study, the FRR-resistant Florence-Aurore and the susceptible Frontana and Ning 7840 were selected. At each developmental stage, roots, stem bases, lower, and apical shoot segments (spikes at flowering stage) were tested. For all three cultivars and during the entire wheat development, the presence of the pathogen and DON toxin were confirmed in the lower and apical shoot segments as well as in the flag leaf nodes and spikes at late flowering (Supplementary Fig. S8A to C). This finding is consistent with the microscopic observation that, by 28 dai, the seedling stem apex of Florence-Aurore also was increasingly invaded by F. graminearum (Fig. 5P and Q). At flowering, the roots of all cultivars were pathogen-free but not toxin-free, while the pathogen remained in the stem bases. The upper noninoculated main stem internodes and leave blades were symptomless when sampled. However, at the stem elongation and flowering stages, the plants of all three genotypes occasionally displayed wilting symptoms, namely, premature ripening of shoots and 'whitehead' appearing as bleached spikes (Supplementary Fig. S8D). Observations made in this study have to be considered to be preliminary results, which, however, demand further experiments to proof i) the described pathogen and toxin spread, ii) the functional role of DON during root and plant colonization, and iii) the possible spike colonization as an ultimate consequence of FRR.

\section{DISCUSSION}

\section{The characteristics of wheat seedling resistance against $\boldsymbol{F R R}$.}

The described histopathological and disease severity studies demonstrated that FRR develops in three distinct phases, each characterized by specific $F$. graminearum-wheat interactions (Table 4), clearly differing between resistant and susceptible wheat genotypes. Florence-Aurore was one of the two genotypes that exhibited a partial resistance to FRR due to the low level of fungal propagation, biomass loss, and symptom development (Fig. 1A and B). Briefly, the resistance of Florence-Aurore was also found using the soil-infestation method (Wang et al. 2006), which we applied to additionally test the $F$. graminearum root-infection ability. After passing a $F$. graminearum-infested soil zone, seedling roots of Florence-Aurore, Line 172.11, and Tobak showed, between 10 and 21 dai, average infection levels of $0.5,6.1$, and $25.0 \%$, respectively, generally coinciding with results of root-dip inoculations.

Microscopic examinations revealed that the resistance of Florence-Aurore is explained by a disturbed migration of $F$. graminearum hyphae from the root epidermis into the cortex (Fig. 5E). These observations correspond to the definition that partial resistance is first characterized by quantitative limitation of pathogen growth (Vergne et al. 2010). In addition, resistance to root colonization coincides with an impaired disease spread, and indications for a (temporary) wheat defense acting in the stem were found in Florence-Aurore. At 14 dai, nonfungal green fluorescence signals were observed in bundle sheath cells surrounding the vascular tissue (Fig. $5 \mathrm{H}$ and I). Taking into account that $F$. graminearum essentially colonizes stem tissue as a vascular pathogen (Fig. 5F), a protective host response in consequence to beginning fungal stem invasion can be assumed. The chitin-specific dye WGA Alexa Fluor 488 used to visualize fungal hyphae can (as an exception) also stain enriched hydroxyproline-rich glycoproteins of secondary plant cell walls (Lannoo et al. 2006). Such proteins might constitute a cell-wall strengthening (Chazotte 2011), which is able to slow down the growth of $F$. graminearum in vascular bundles (Ribichich et al. 2000). A similar autofluorescence has been observed in cortical root cells invaded by $F$. culmorum but was not associated with an inhibited penetration, probably because the examined wheat genotype Genio is susceptible to FRR and FCR (Beccari et al. 2011).

The observed resistance to FRR did not provide protection against initial infection of the root epidermis, which underpins the partial nature of root rot resistance. Microscopic studies on FHB suggested that the early and main infection stages in susceptible and (partially) resistant genotypes are undistinguishable (Boenisch and Schäfer 2011; Pritsch et al. 2000). However, it is difficult to reliably assign supposed differences in the infection structures with resistance or susceptibility. This constraint has been reported for FHB (Boenisch and Schäfer 2011) and was similarly observed during microscopy on root-infection process. Nevertheless, already at early disease stages, FRR resistance differed from susceptibility by minimal fungal biomass accumulation and root necrosis rate, which, indeed, suggests an impaired root infection.

In addition, the observed resistance was not able to completely prevent disease spread into aerial plant parts. Migrations of $F$. graminearum into the stem base, stem apex, and leaf blade tissues of the resistant Florence-Aurore were, at best, sporadic until 28 dai, at which timepoint those migrations had increased sharply (Table 4). Especially in necrotic stem-base sections, colonization levels comparable to those of susceptible Line 1105.16 were encountered. Indeed, in the period from 7 to 21 dai, a developing pathogen migration into the stem bases of resistant genotypes Florence-Aurore (Fig. 1) and Line 162.11 could be recognized, based on visible symptom assessments, albeit much less severe as compared with the susceptible genotypes. Moreover, our study on the systemic colonization of distal, noninoculated plant tissues provided clues for an unrestricted disease spread throughout the shoot, reaching up to the spikes. Occasionally, we observed premature wilting of shoots and spikes at later developmental stages, which are typical symptoms of a water deficit. Since the plants were watered regularly and stem-base tissues were found to be colonized by $F$. graminearum until flowering stages, they might be a result of either stem-base necrosis (Mudge et al. 2006), reduced water translocation due to fungal hyphae blocking the stem-base vasculature (Martín-Rodrigues et al. 2015), or both.

In respect to fungal ability to invade the upper shoot, no genotypic differences were found, even though different responses to FRR and FHB (Fig. 3) were represented by the tested genotypes Florence-Aurore, Frontana, and Ning 7840. In summary, our observations indicate that, once the pathogen establishes contact with stem-base tissues, the fungal spread rate exceeds, over time, the possibility of seedlings to stop fungal attack, and pathogen proliferation is favored. A similar 
observation has recently been reported for $F$. circinatum causing root rot in seedlings of the radiata pine (Pinus radiata) tree (Martín-Rodrigues et al. 2015).

One possible explanation comes from our discovery that pathogen invasion of upper stem and leaf tissues proceeds symptomless, while seedling stem bases showed the typical necrosis symptoms. This indicates a switch from a destructive necrotrophic to a nondestructive endophytic growth, similar to observations made for $F$. graminearum and $F$. pseudograminearum after stem-base inoculations in wheat (Mudge et al. 2006). Explicit necrotrophic fungi can switch to an asymptomatic endophytic lifestyle (Delaye et al. 2013). Nevertheless, this can be accompanied by the release of virulence factors including mycotoxins to suppress plant defense (Rodriguez Estrada et al. 2012; Rodriguez et al. 2009). We hypothesize that $F$. graminearum, in its endophytic (probably nonmutualistic) phase, releases DON at a low level, to disrupt programmed cell death rather than to kill host cells (Diamond et al. 2013). This might be part of a 'balanced antagonism' strategy (Maciá-Vicente et al. 2009) in which the pathogen feeds from extracellular exudates and probably escapes plant defenses, reminiscent of a strategy evolved by $F$. graminearum during spike rachis colonization (Brown et al. 2010). Moreover, $F$. graminearum colonizes stem tissue as a vascular pathogen, and the vasculature of the spike rachis has been reported to be an avenue toward as-yet-uninfected spikelets in both resistant and susceptible wheat cultivars (Ribichich et al. 2000). Individual fungal strains can act either as a pathogen or an endophyte in the same host (Alvarez-Jubete et al. 2010; Promputtha et al. 2010). Thereby, factors such as abiotic environment or plant age might determine fungal behavior (Delaye et al. 2013; Schulz and Boyle 2005).

Since pathogen migration into the shoot also coincided with the end of seedling stages and the beginning of tillering, plant age might be an additional factor to be considered. Moreover, during this transition phase, first invasions of the inner root layer were also microscopically detectable for the resistant Florence-Aurore. Plant age can not only influence fungal virulence but can also determine changes in wheat responses to FRR reminiscent of an adult plant resistance. Such a scenario has been suggested for susceptible reactions displayed by seedlings of FHB-resistant wheats (e.g., Sumai 3 and Wangshuibai) after stem-base infection with $F$. graminearum (Wu et al. 2005) and F. asiaticum (Li et al. 2010). Support for this assumption comes from the genotype rankings presented in our study, because major FHB resistances obviously did not protect against FRR, at least not during seedling stages (Fig. 3).

\section{$F$. graminearum root infection combines processes typical for root and floret invasion.}

That root infections by soil-borne-inoculum may be a component of the $F$. graminearum disease cycle has been presumed for some time. However, nothing concrete was known about the ability and the structures evolved by $F$. graminearum in the process of root infection (Kazan et al. 2012). During the early stage of pathogenesis, germinated macroconidia did not immediately penetrate roots (Fig. 4A). Instead, they colonized the root surface by a dense net-like mycelium (Fig. 4B) prior to the initial infection of root epidermis and migration into cortex cells at 1 dai (Fig. 4C, D, and E). This mode of pathogenesis resembles root-infection processes described for the classical root and crown rot pathogens F. culmorum (Beccari et al. 2011; Peraldi et al. 2011) and F. equiseti (Maciá-Vicente et al. 2009). Penetrations of wheat roots at 1 dai, verified by microscopy and qPCR diagnosis, are likely due to simple hyphal swellings observed in the vegetative mycelium of $F$. graminearum, reminiscent of infection structures (hyphopodia) typical for root- pathogenic fungi (Howard 1997). The formation of hyphopodia by a Fusarium pathogen has, so far, solely been reported for F. circinatum during pine root infections (Martín-Rodrigues et al. 2015).

From 3 dai on, more complex infection structures were observed, indicating the main infection stage. At this stage, coral-like hyphal mats (Fig. 4I) were found that morphologically coincide with infection cushions formed by $F$. graminearum during the main infection stage of FHB (Boenisch and Schäfer 2011; Rittenour and Harris 2010). Similar to wheat floral tissues (Boenisch and Schäfer 2011), the infection cushions on roots originated from runner hyphae together with foot structures (Fig. $4 \mathrm{H})$ and were surrounded by necrotic root cells, demonstrating a role in root infection. The foot structures on roots were morphologically similar to those formed by $F$. graminearum on wheat florets, presumed to be bulbous infection hyphae (Boenisch and Schäfer 2011). Bulbous infection hyphae and infection cushions are important for head infections (Rittenour and Harris 2010), and the former were also observed for $F$. graminearum infecting coleoptile of Brachypodium distachyon (Peraldi et al. 2011). The development of infection cushions on roots is, however, remarkable, as it demonstrates a biphasic strategy of $F$. graminearum in which the early stage resembles a typical root pathogen and the later stage is similar to the floret infection process.

Besides commonalities in the structures evolved by F. graminearum for root and spike infection, the chronology of both infection processes also shows similarities. Thus, on wheat and barley spikes, the initial infection process was found to proceed during the first 2 dai. Also, on spikes, F. graminearum spores germinated within 0.5 dai and first minor colonizations of palea tissues were reported for timepoints 2 dai, limited to subepidermal hyphal growth (Jansen et al. 2005; Pritsch et al. 2000; Wanjiru et al. 2002). By 4 to 5 dai, rapid colonizations of all cell types were found (Brown et al. 2010) and, accordingly, from 3 dai on, runner hyphae, foot structures, lobate appressoria, and infection cushions were detected on spike tissues, accompanied by necrotic lesions and sporulation structures (Boenisch and Schäfer 2011). The onset of disease spread from initially infected spikelets to noninfected spikelets via the rachis was reported for 5 dai (Brown et al. 2010). This timing, which in its entirety describes the susceptible interaction, is almost identical to our observations on FRR.

However, we did not find lobate appressoria on roots, which have been observed on infected palea (Boenisch and Schäfer 2011). In this aspect, our results correspond to observations made for the pathogens Rhizoctonia solani and $R$. oryzae penetrating potato (Solanum tuberosum) roots via infection cushions and foliar tissue via lobate appressoria (Weinhold and Sinclair 1996). In addition, the pathogens Magnaporthe grisea (Sesma and Osbourn 2004), M. oryzae (Marcel et al. 2010), and Colletotrichum graminicola (Sukno et al. 2008) infect foliar tissues by melanized appressoria but roots solely by hyphopodia-like structures, morphologically similar to those that we observed on wheat roots. The formation of appressoria on rice (Oryzae sativa) leaves by $M$. grisea and $M$. oryzae is controlled by cAMP-mediated signaling processes that are not essential for root penetration (Sesma and Osbourn 2004; Tucker et al. 2010). Therefore, it was assumed that the ability to use either hyphopodia or appressoria permits pathogens to adapt their penetration mechanism to the specific properties of the target organ (Marcel et al. 2010). Such a scenario might also apply for $F$. graminearum, because the cAMP-mediated signaling seems to function during Fusarium spike infection in a way similar to foliar infection by Magnaporthe pathogens (Bormann et al. 2014). 


\section{Plant tissue-adapted colonization strategies} of $\boldsymbol{F}$. graminearum.

The observed colonization pathway of $F$. graminearum seems to correspond to specific tissues and developmental stages of wheat. Originating from the epidermal cell layer, $F$. graminearum systematically invades the parenchyma cells of the cortex (Fig. 5C and D) but was not observed to colonize the stele (primary vascular system), as also known from $F$. culmorum (Beccari et al. 2011; Peraldi et al. 2011). With the migration into noninoculated stem segments, $F$. graminearum colonized both the parenchyma cells and the vascular bundles (Fig. $5 \mathrm{~F}$ and $\mathrm{N}$ to Q). For crown rot disease, contradicting observations on Fusarium colonization of noninoculated upper stem parts were reported. For instance, Mudge et al. (2006) did not observe $F$. graminearum in the vascular bundles of upper internodes but they proved the fungal migration into wheat spikes, whereas Clement and Parry (1998) detected $F$. graminearum hyphae in the vasculature of stems but no migration into heads.

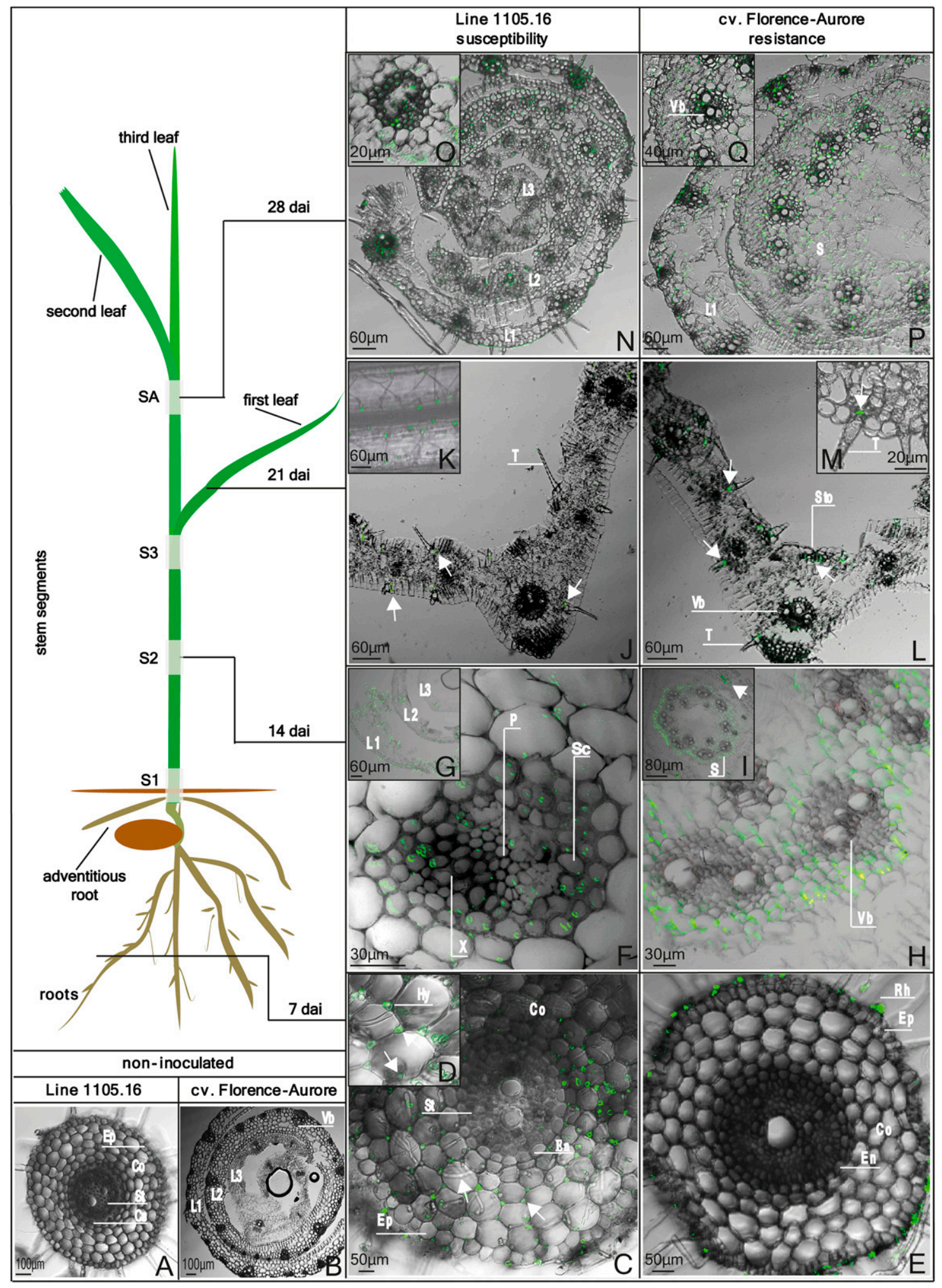


It was argued that vascular tissue in wheat stem bases is surrounded by lignified parenchyma cells (the bundle sheath) hampering fungal penetration, while the pith parenchyma represents an unrestricted pathway with access to stored carbohydrates (Mudge et al. 2006). However, our results demonstrate the presence of hyphae in the bundle sheaths. It is, therefore, possible that, growing from roots, $F$. graminearum invades vascular bundles before lignification occurs, possibly in the course of stem elongation (Dharmawardhana et al. 1992). As reported before, the bundle sheath was supposed to be the location of a protective response in stem tissue of resistant wheat Florence-Aurore.

Our observations on stem-base colonizations demonstrated that $F$. graminearum invaded almost simultaneously the outer two leaf sheaths of the lower stem base and reached the central leaf sheath after 3 to 7 days (Fig. 5F to I), while the vertical spread into the seedling apex required approximately 11 to 14 days under our conditions (Fig. $5 \mathrm{~N}$ to Q). Our hypothesis is that, originating from roots, $F$. graminearum migrates rather unhindered into the stem base via adjacent epidermis and parenchyma cells at the root-stem junction. In fact, indications of an 'epidermis-parenchyma route' for disease spread were found for FRR caused by $F$. culmorum (Beccari et al. 2011) and for FHB caused by $F$. graminearum (Brown et al. 2010). Such a route would explain the first minor hyphae migration into the lower stem base (S1) of Florence-Aurore at 10 dai and the almost simultaneous infection of lower leaf blades in Line 1105.16 at 10 dai, now via the parenchyma connecting the leaf sheath and leaf blade. After entering leaf blades, $F$. graminearum exclusively targeted cells directly beneath or inside the trichomes, indicating a pathogenic strategy to use trichomes as a passage to the leaf surface for enabling disease dispersal to upper plant parts or neighboring plants. For $F$. graminearum, the ability to infect leaves via trichomes (Peraldi et al. 2011) and to germinate on the leaf surface after a systemic leaf colonization (Guenther and Trail 2005) has been demonstrated.

In conclusion, the high ability of $F$. graminearum to act as a root pathogen has been demonstrated and merits further research. The finding that $F$. graminearum, actually a paradigm for Fusarium head blight, has retained this ability suggests an advantage to the pathogen, because successful root infection was found to be associated with complex, specialized structures and processes. Moreover, essential similarities were found between FRR and FHB that concerned both the fungal structures and the timing of disease establishment or progression. So far, roots have received little scientific attention as a gateway to Fusarium colonization of cereal crops. Furthermore, $F$. graminearum is typically not considered as a major contributor to soil-borne diseases, in contrast to its relatives $F$. culmorum and $F$. pseudograminearum. Our findings, however, indicate a close relationship of $F$. graminearum to major root-infecting pathogens of substantial economic significance, such as take-all disease of wheat. The threat caused by a possible change of pathogenic behavior, for instance, as a consequence of altered agricultural practices is an issue of major concern. This would have significant implications for resistance breeding and disease control in crop plants, especially against the background of a predictable intensification of crop production. Our observations on disease and symptom development are based on greenhouse investigations, and the epidemiological significance of root infection remains to be addressed. In addition, it will be an important next goal to determine the molecular and genetic mechanisms behind the resistance to FRR, with a view on FHB as well as on possible plant age or tissue specific shifts in the wheat $-F$. graminearum interaction. Finally, investigation of the basic events that have led to the ability of $F$. graminearum to infect both wheat roots and spikes is an attractive area for future research.

\section{MATERIALS AND METHODS}

\section{Plant and fungal material.}

Prior to sowing, wheat seeds were sterilized in $6 \%$ sodium hypochlorite solution (double-distilled water, $\mathrm{NaClO} 12 \% \mathrm{vol} / \mathrm{vol}$ ) for $40 \mathrm{~min}$ and were washed ten times with double-distilled water. Seeds were sown in noninfested, autoclaved sand and were cultivated in the climate chamber with a 16-h photoperiod of 22 and $18^{\circ} \mathrm{C}$ (under cool-white light illumination) and $60 \%$ humidity until Zadok's stage (Z) 11 (Zadoks et al. 1974). Macroconidia of $F$. graminearum isolate IFA 65 (Inter-University Department of Agrobiotechnology, IFA Tulln, Austria) was grown on the synthetic nutrient agar medium Spezieller Nährstoffarmer agar (Leslie and Summerell 2006) at $20^{\circ} \mathrm{C}$ under cool-white and near-UV light illumination. The macroconidia suspension was prepared according to Gottwald et al. (2012). The final concentration was determined with a hemocytometer adjusted to $5 \times 10^{4}$ conidia per milliliter.

\section{Root-dip inoculation and plant tissue sampling.}

Inoculations were carried out in accordance with methods described for root inoculations with $F$. oxysporum and Verticillium dahliae (Freeman and Rodriguez 1993; Trapero et al. 2013). Prior to inoculation, seedling roots were carefully removed from noninfested, autoclaved sand by submerging in water to obtain intact roots. Five seedlings each were transferred into a small flat tray by submerging their bare root systems in $5 \mathrm{ml}$ of $F$. graminearum macroconidia suspension (seedlings were held in place by a slot in a styrofoam plug) and were kept on a rotary shaker for $2 \mathrm{~h}$. Additionally, hypocotyl and stem above the roots were beforehand wrapped in aluminum foil to protected them from undesired inoculations. For control plants, mock inoculations were performed with double-distilled water instead of fungal suspension. After root

Fig. 5. Colonization of root and above-ground plant parts in partially resistant cultivar Florence-Aurore and susceptible Line 1105.16. A, Uninfected root of Line 1105.16. B, Uninfected stem base of Florence-Aurore. C and D, Root cortex colonization with extra- and intercellular hyphae in a cross section of Line 1105.16 at 7 days after root inoculation (dai). Hyphae growing from cell to cell via the symplasmic pathway are marked by white arrows. Hyphae appear nonstained in the overlay images because they are located out of the confocal plane. E, Root cross sections of Florence-Aurore obtained at 7 dai, showing the hyphae restriction to the epidermis layer. F, Infected vascular bundle of stem-base segment S1, obtained from Line 1105.16 at 14 dai. G, Detailed image showing fungal colonization in the stem-base leaf sheath. H, Stem base segment S1 obtained from Florence-Aurore at 14 dai, with strong nonpathogenic fluorescence signals in the stem bundle sheath, a layer of compactly arranged parenchyma surrounding the vasculature. I, Nonpathogenic fluorescence signals in the bundle sheath of recently developed stem tissue and low fungal colonization in the external leaf sheath (white arrow). J, First leaf blade obtained from Line 1105.16 at 21 dai, showing hyphae in cells at or in trichomes. K, Image from leaf surface showing hyphae at trichomes. L, First leaf blade obtained from Florence-Aurore at 21 dai, showing hyphae in cells at or in trichomes. M, Hyphae at the base of trichome. N, At the stem apex, the leaf crown of Line 1105.16 with fungal colonization of parenchyma and vascular tissues at 28 dai. O, Hyphae in the bundle sheath and vascular bundle. P, At the stem apex, image shows fungal colonization in the upper stem of Florence-Aurore at 28 dai. Q, Detailed image of P, showing invaded vascular bundle. Images were obtained by confocal laser scanning microscopy on WGA Alexa Fluor 488-stained hyphae (green signals). Co = cortex, Cs = casparian stripe, Ep = epidermis, En = endodermis, Hy = hyphae, L1 = leaf sheath 1 , L2 = leaf sheath 2, L3 = leaf sheath 3, $\mathrm{P}=$ phloem, $\mathrm{Rh}=$ root hair, $\mathrm{S}$ stem, $\mathrm{Sc}=$ sclerenchyma, $\mathrm{St}=$ stele, $\mathrm{Sto}=$ stomata, $\mathrm{T}=$ trichomes, $\mathrm{Vb}=$ vascullar bundle, and $\mathrm{X}=\mathrm{xylem}$. 
inoculation, five seedlings each were planted in pots $(7.5 \times$ $7.5 \times 8.0 \mathrm{~cm}$ ) with noninfested, autoclaved sand. Plants were cultivated in a climate chamber with a 16-h photoperiod at 22 and $18^{\circ} \mathrm{C}$ (under cool-white light illumination) and $60 \%$ humidity. To avoid additional stress factors, each pot was watered as required and weekly fertilized with $100 \mathrm{ml}$ of Wuxal Super (Manna, Düsseldorf, Germany), according to the manufacturer's specifications. To keep seedlings free from contamination, prior to cultivation and inoculation, the climate chamber was cleaned by surface disinfection against plant-pathogen organisms with MENNO Florades (Menno Chemie Norderstedt, Germany), according to the manufacturer's specifications. For the time-course study, root samples were collected at $0.5,1,3,5,7,10,14$, and 21 dai. Severity assessments are based on 20 seedlings per genotype and treatment; visible symptoms on roots and stem bases were individually rated on each seedling and, for qPCR diagnosis, the roots of five seedlings, each, were sampled per genotype or treatment.

\section{DNA isolation from wheat roots and leaves.}

The isolation of plant genomic DNA (gDNA) was carried out by applying the Method C described by Brunner et al. (2009). After isolation, gDNA concentration and quality were determined using the NanoDrop N-1000 (Thermo Fisher Scientific, Waltham, MA, U.S.A.). The gDNA of inoculated and noninoculated seedling roots was used to quantify root and $F$. graminearum biomass. The gDNA of noninoculated seedling leaves was used as external wheat DNA standard in the reference gene-based qPCR method. Therefore, gDNA was serially diluted with sterile double-distilled water $(100,50,25,6.25$, 1.5625 , and $0.39 \mathrm{ng}$ of wheat DNA per microliter) and was kept at $-20^{\circ} \mathrm{C}$ until use.

\section{DNA isolation from fungal mycelia.}

Potato dextrose broth was inoculated with a $2 \times 10^{5}$ macroconidia suspension of $F$. graminearum and was incubated on a rotary shaker at $28^{\circ} \mathrm{C}$ for 3 to 5 days. The mycelium was harvested by filtration and freeze-dried and gDNA was isolated by applying the CTAB-based method described by Brandfass and Karlovsky (2008). DNA concentration and quality was determined as described for the DNA isolation from plant tissues. The gDNA was used as Fusarium standard in the reference gene-based qPCR and, therefore, was serially diluted with sterile double-distilled water $(50,10,5,1,0.5$, and $0.1 \mathrm{ng}$ of $F$. graminearum DNA per microliter) and kept at $-20^{\circ} \mathrm{C}$ until use.

\section{Real-time qPCR measurement of fungal and root gDNA.}

Analyses were performed on a 7500 Fast real-time PCR system (Applied Biosystems, Foster City, CA, U.S.A.). Primers F. graminearum 16N-F (ACAGATGACAAGATTCAGGCACA) and $F$. graminearum $16 \mathrm{~N}-\mathrm{R}$ (TTCTTTGACATCTGTTCAACC CA) were used to amplify a $F$. graminearum-specific fragment (Nicholson et al. 1998). The F. graminearum specificity of primers has previously been determined (Brandfass and Karlovsky 2006; Nicholson et al. 1998). In addition, we have negatively tested the F. culmorum isolate Fc002 (School of Life Sciences Weihenstephan, Munich, Germany). Wheat DNA was quantified by amplification of the wheat Ubiquitin gene (DQ086482/ Ta.28553.1.S1_s_at) with primers Ubi-F (CCCTGGAGGTG GAGTCATCTGA) and Ubi-R (GCGGCCATCCTCAAGCTGC TTA). The Ubiquitin gene has been selected according to Gottwald et al. (2012) and was tested for expression stability and specificity in root tissues. In separate reactions, the $F$. graminearum $16 \mathrm{~N}$ and Ubi primers were tested for template specificity. Both the fungal templates used for plant-specific primers and the plant templates used for fungal-specific primers gave no amplification product.

For both the $F$. graminearum $16 \mathrm{~N}$ and the Ubiquitin assay the amplification mix consisted of $1 \mu$ of template DNA, $5 \mu \mathrm{l}$ of Roche FastStart universal SYBR green master (Roche Diagnostics $\mathrm{GmbH}$, Mannheim, Germany), $2 \mu \mathrm{l}$ of double-distilled water, and $1 \mu \mathrm{l}$ each of forward and reverse primer $(10 \mathrm{pmol} / \mu \mathrm{l})$. The qPCR was performed for both assays without changes, in accordance with the cycling protocol published by Brandfass and Karlovsky (2006), which was optimized for the detection of low F. graminearum biomass concentrations. Melting curves were analyzed using the Dissociation Curves Software (Applied Biosystems), to ensure that only a single product was amplified.

The average amount of $F$. graminearum in wheat roots and the infection percentage of root samples (relative fungal biomass) were calculated by using the reference gene-based DNA quantification method and formula published by Brunner et al. (2009). PCR plates were split into two parts, each containing one of the two dilution series and eight root samples in three technical replicates. Finally, the infection percentage was calculated as the average of the four biological replicates. No fungal biomass was detected in the roots of control plants analyzed at any timepoint.

\section{Disease severity assessments.}

At each timepoint, root biomass (obtained from reference gene-based qPCR), root length, and shoot length were measured for inoculated and noninoculated control plants, and the percentage change (D) between both treatments was calculated: $\mathrm{D}=($ control - inoculated $) /$ control $\times 100$. Symptoms on roots and stem bases were each rated by applying browning and symptom extension scales (0 to 4$)$ to each single seedling. Symptoms on roots and stem bases were each rated by applying the browning and symptom extension scales to each single seedling. The browning scale ranged from $0=$ symptomless, 1 = slightly necrotic, 2 = moderately necrotic, 3 = severely necrotic, and $4=$ completely necrotic (Beccari et al. 2011). The extension scale ranged from $0=$ no lesions, $1=1$ to $24 \%, 2=24$ to $49 \%, 3=50$ to $75 \%$, and $4=>75 \%$ discoloration of root or stem base (Percy et al. 2012). Finally, a genotype timepointspecific root and stem-base symptom index (RSI and SbSI) was calculated using the equation: $\mathrm{RSI}$ or $\mathrm{SbSI}=(\mathrm{E} 1+\mathrm{E} 2+\ldots+\mathrm{E} n / n)+$ $(\mathrm{B} 1+\mathrm{B} 2+\ldots+\mathrm{B} n / n)$; where $\mathrm{B}$ and $\mathrm{E}$ represent the parameter browning and extension index and $n$ the number of assessed individuals per genotype and treatment (Piccinni et al. 2000). In this study, the stem base was referred to subcrown and first stem internode. The control plants analyzed at any timepoint were symptom free.

\section{FDI.}

The FDI incorporates all six severity parameter assessed in this study: i) relative fungal biomass, percentage change in ii) root biomass, iii) root length, and iv) shoot length, and v) root and vi) stem-base symptom rating. Prior to FDI calculation, the measured values of each severity parameter were transferred into dimensionless susceptibility index (SI) values to allow normalization and direct comparison between different types of value. SI values were calculated using the equation $\mathrm{SI}=(\mathrm{XT} x)$ / (Y); where $\mathrm{X}$ represents the measured value for each genotype and timepoint ( $\mathrm{T} x$ ) and $\mathrm{Y}$ the corresponding overall mean calculated over all 12 wheat genotypes and timepoints (based on the equation published by Mason et al. [2010]). For each genotype and timepoint the respective FDI values were calculated as the sum of SI values. For the FDI, all severity parameters were handled with equal valence. For each genotype, average FDI values over time were used to rank genotypes according to their overall performance under disease conditions. 


\section{Statistical analyses.}

All statistical analyses were performed by using the software SPSS 20 (IBM SPSS Statistics 20; IBM Corp., Armonk, NY, U.S.A.). Treatment effects were statistically tested for each timepoint and genotype by one-way ANOVA. The rANOVA was used to assess the time course of FRR disease progression. Since the Mauchly's test for sphericity violated the equality assumption, the Greenhouse-Geisser correction was applied to adjust the degrees of freedom appropriately. For multiple comparisons, the Bonferroni adjustment (correction for Type I error) was applied. The mean profile plots (estimated marginal means) were applied to interpret significant time $\times$ treatment interactions. Two-way rANOVA was performed to test treatment and time effects on the traits root biomass, root length, and shoot length. Mixed rANOVA was performed to test for time effects (changes) in the disease progress in terms of fungal growth, reduction in root and shoot biomass of disease seedlings, and necrosis development on roots and stem bases. The error bars given in the graphs of time-course severity data indicate standard error of the mean, which reflects the uncertainty in the mean and its dependency on the sample size $(n)$.

\section{Tissue generation and preparation for microscopy analyses.}

Root-dip inoculations were carried out for Florence-Aurore and Line 1105.16. Seedling roots were inoculated in three biological replications, each with five different plants per investigated timepoint. Bright-field microscopic studies were done on roots obtained at $0.5,1,3$, and 5 dai. Confocal laser scanning microscopic studies were done at the timepoints 7,10 , 14, 21, and 28 dai in root, stem, and leaf blade tissues. The seedling stem base was divided into three segments (S1 to S3) supplemented by the stem apex (SA), as illustrated in Figure 5. For each tissue part (S1, S2, S3, SA), three sections were analyzed. The same procedures were also applied to noninoculated (control) roots. Control roots were found to be free from $F$. graminearum and other possible fungal hyphae, since no fungal structures (bright-field microscopy) or fluorescence signals (confocal laser scanning microscopy) were observed. In addition, inoculated and noninoculated tissues were tested for possible fungal contaminations and $F$. graminearum presence by fungal reisolations from $2-\mathrm{cm}$ tissue segments. Reisolation as well as cultural and morphological identification of $F$. graminearum were done as described by Gottwald et al. (2001) and Leslie and Summerell (2006).

Roots were fixed by incubation in a mixed solution of chloroform, 96\% ethanol, and trichloroacetic acid (1:4:0.15). The fixed roots were subjected to hand-section and were transferred to an observation slide. Stem and leaf blade tissues were fixed by freezing in a metal mold with $4 \%$ (wt/vol) CMC solution (carboxymethyl cellulose sodium salt) (Sigma-Aldrich, St. Louis), by immersing the mold into a coolant mixer (hexane and dry ice). Afterward, the CMC block was sliced to a thickness of $20 \mu \mathrm{m}$, using a cryrostat (HM 525 cryostat; Thermo Scientific, Dreieich, Germany). The embedding material was removed carefully with a painting brush, to prevent the distortion of tissue. Finally, the section was thawed and mounted on a microscope glass slide. Glass slides were stored in a plastic box in $4^{\circ} \mathrm{C}$ to keep humidity.

\section{Microscopy analyses.}

Bright-field microscopy was performed with transmitted light, using a Zeiss Axioplan 2 imaging and Axiophot 2 (Carl Zeiss, Jena, Germany) microscope equipped with a Zeiss Apotome for trypan blue (Sigma-Aldrich)-stained fungal structures. For fluorescence microscopy, the above-mentioned microscope with the same equipment was applied for analyzing wheat germ agglutinin Alexa Fluor 488 conjugate (WGA)
(Invitrogen, Carlsbad, CA, U.S.A.) -stained fungal structures with a UV lamp HAL 100. Green fluorescent protein was excited with 480 to $500 \mathrm{~nm}$ and detected at 510 to $530 \mathrm{~nm}$. Images were taken with a Zeiss Axio Cam MRm CCD camera. Image processing was carried out by Zeiss AxioVision software (version 4.8.1).

Confocal laser scanning microscopy was performed with a Leica TCS SP2 microscope (Leica Microsystems, Heidelberg, Germany) after WGA staining. WGA was excited by the 488-nm line of the argon/krypton laser (Omnichrome, Chino, CA, U.S.A.). For observation at $510 \mathrm{~nm}$ and autofluorescence detection at 550 to $650 \mathrm{~nm}$, a long-pass filter was used. Digital images were processed with Adobe Photoshop to optimize brightness, contrast, and color and to enable an overlay of the photomicrographs. Staining with trypan blue and WGA were done as described by Boenisch and Schäfer (2011) and (Thatcher et al. 2009), respectively.

\section{Assessment of fungal colonization and DON translocation.}

Seedlings of Florence-Aurore, Frontana, and Ning 7840 were inoculated with either $F$. graminearum or double-distilled water, using the root-dip inoculation procedure. After inoculations, five seedlings each were cultivated in one pot $(11.5 \times$ $11.5 \times 12 \mathrm{~cm})$ with $1: 2(\mathrm{vol} / \mathrm{vol})$ mixture of noninfested, autoclaved sand and soil (Fruhstorfer Erde, Hawita Gruppe $\mathrm{GmbH}$, Vechta, Germany). Disease spread was investigated at four stages, namely, seedling (Z13, three unfolded leaves), tillering (Z21-22), early stem elongation (Z32), and late flowering stage (Z64-68). For each genotype and wheat stage, 30 plants were grown (20 inoculated and 10 noninoculated), except the flowering stage, at which, in total, 45 plants were inoculated. At each growth stage, roots, stem bases, and stem apex (newly developed stem internode) were sampled. At flowering, spike tissues were additionally sampled. At each timepoint, 20 plants were randomly pooled into two samples and were used to test for $F$. graminearum presence and for contamination with the mycotoxin DON. The qPCR was applied for testing $F$. graminearum presences as reported by Mudge et al. (2006), using the $F$. graminearum $16 \mathrm{~N}$ assay. DNA from the $F$. graminearum isolate IFA 65 was used as positive control, DNA from noninoculated wheat plants and non-DNA-templates were used as negative controls. The DON toxin was detected using the Ridascreen Fast DON kit (R-Biopharm AG, Darmstadt, Germany) for ELISA. Each sample was measured in three technical repeats, and DON was quantified using a Tecon Sunrize 96-well microplate reader (Tecan $\mathrm{GmbH}$, Grailshein, Germany). Finally, DON concentration was calculated by using the Rida Soft Win (R-Biopharm AG, Darmstadt, Germany).

\section{ACKNOWLEDGMENTS}

We thank H. Buerstmayr and M. Lemmens (University of Natural Resources and Applied Life Sciences, Department for Agrobiotechnology, Vienna, Austria) for kindly providing the F. graminearum inoculum. We also thank R. Hueckelhoven (Center of Life and Food Sciences Weihenstephan, TU München, Germany) for kindly providing the $F$. culmorum inoculum. We are grateful to S. Kontowski (Pflanzenzucht W. von Borries Eckendorf, Leopoldshöhe, Germany) for kindly providing seed material of the investigated wheat genotypes. We are also thankful to S. Tzigos and all colleagues in the Department of Plant Breeding for excellent technical assistance and help of all kinds. This work was partially supported by China Scholarship Council.

\section{LITERATURE CITED}

Alvarez-Jubete, L., Wijngaard, H., Arendt, E. K., and Gallagher, E. 2010. Polyphenol composition and in vitro antioxidant activity of amaranth, quinoa buckwheat and wheat as affected by sprouting and baking. Food Chem. 119:770-778. 
Badea, A., Eudes, F., Graf, R. J., Laroche, A., Gaudet, D. A., and Sadasivaiah, R. S. 2008. Phenotypic and marker-assisted evaluation of spring and winter wheat germplasm for resistance to Fusarium head blight. Euphytica 164:803-819.

Beccari, G., Covarelli, L., and Nicholson, P. 2011. Infection processes and soft wheat response to root rot and crown rot caused by Fusarium culmorum. Plant Pathol. 60:671-684.

Bennett, A. J., Bending, G. D., Chandler, D., Hilton, S., and Mills, P. 2012 Meeting the demand for crop production: The challenge of yield decline in crops grown in short rotations. Biol. Rev. Camb. Philos. Soc. 87:52-71.

Boenisch, M. J., and Schäfer, W. 2011. Fusarium graminearum forms mycotoxin producing infection structures on wheat. BMC Plant Biol. 11: 110.

Bormann, J., Boenisch, M. J., Brückner, E., Firat, D., and Schäfer, W. 2014. The adenylyl cyclase plays a regulatory role in the morphogenetic switch from vegetative to pathogenic lifestyle of Fusarium graminearum on wheat. PLoS One 9:e91135.

Bovill, W. D., Ma, W., Ritter, K., Collard, B. C. Y., Davis, M., Wildermuth, G. B., and Sutherland, M. W. 2006. Identification of novel QTL for resistance to crown rot in the doubled haploid wheat population 'W21MMT70' × 'Mendos'. Plant Breed. 125:538-543.

Brandfass, C., and Karlovsky, P. 2006. Simultaneous detection of Fusarium culmorum and F. graminearum in plant material by duplex PCR with melting curve analysis. BMC Microbiol. 6:4.

Brandfass, C., and Karlovsky, P. 2008. Upscaled CTAB-based DNA extraction and real-time PCR assays for Fusarium culmorum and F. graminearum DNA in plant material with reduced sampling error. Int. J. Mol. Sci. 9:2306-2321.

Brown, N. A., Urban, M., van de Meene, A. M., and Hammond-Kosack, K. E. 2010. The infection biology of Fusarium graminearum: Defining the pathways of spikelet to spikelet colonisation in wheat ears. Fungal Biol. 114:555-571.

Brunner, K., Kovalsky Paris, M. P., Paolino, G., Bürstmayr, H., Lemmens, M., Berthiller, F., Schuhmacher, R., Krska, R., and Mach, R. L. 2009. A reference-gene-based quantitative PCR method as a tool to determine Fusarium resistance in wheat. Anal. Bioanal. Chem. 395:1385-1394.

Buerstmayr, H., Ban, T., and Anderson, J. A. 2009. QTL mapping and marker-assisted selection for Fusarium head blight resistance in wheat: A review. Plant Breed. 128:1-26.

Chakraborty, S., and Newton, A. C. 2011. Climate change, plant diseases and food security: An overview. Plant Pathol. 60:2-14

Chazotte, B. 2011. Labeling Membrane Glycoproteins or Glycolipids with Fluorescent Wheat Germ Agglutinin. Cold Spring Harbor Protocols 2011:pdb.prot5623.

Clement, J. A., and Parry, D. W. 1998. Stem-base disease and fungal colonisation of winter wheat grown in compost inoculated with Fusarium culmorum, F. graminearum and Microdochium nivale. Eur. J. Plant Pathol. 104:323-330.

Covarelli, L., Beccari, G., Steed, A., and Nicholson, P. 2012. Colonization of soft wheat following infection of the stem base by Fusarium culmorum and translocation of deoxynivalenol to the head. Plant Pathol. 61:1121-1129.

Cuomo, C. A., Güldener, U., Xu, J. R., Trail, F., Turgeon, B. G., Di Pietro, A., Walton, J. D., Ma, L. J., Baker, S. E., Rep, M., Adam, G., Antoniw, J., Baldwin, T., Calvo, S., Chang, Y. L., Decaprio, D., Gale, L. R., Gnerre, S., Goswami, R. S., Hammond-Kosack, K., Harris, L. J., Hilburn, K., Kennell, J. C., Kroken, S., Magnuson, J. K., Mannhaupt, G., Mauceli, E., Mewes, H. W., Mitterbauer, R., Muehlbauer, G., Münsterkötter, M., Nelson, D., O'donnell, K., Ouellet, T., Qi, W., Quesneville, H., Roncero, M. I., Seong, K. Y., Tetko, I. V., Urban, M., Waalwijk, C., Ward, T. J., Yao, J., Birren, B. W., and Kistler, H. C. 2007. The Fusarium graminearum genome reveals a link between localized polymorphism and pathogen specialization. Science 317:1400-1402.

Delaye, L., García-Guzmán, G., and Heil, M. 2013. Endophytes versus biotrophic and necrotrophic pathogens-Are fungal lifestyles evolutionarily stable traits? Fungal Divers. 60:125-135.

Den Herder, G., Van Isterdael, G., Beeckman, T., and De Smet, I. 2010. The roots of a new green revolution. Trends Plant Sci. 15:600-607.

Dharmawardhana, D. P., Ellis, B. E., and Carlson, J. E. 1992. Characterization of vascular lignification in Arabidopsis thaliana. Can. J. Bot. 70:2238-2244.

Diamond, M., Reape, T. J., Rocha, O., Doyle, S. M., Kacprzyk, J., Doohan, F. M., and McCabe, P. F. 2013. The Fusarium mycotoxin deoxynivalenol can inhibit plant apoptosis-like programmed cell death. PLoS One 8: e69542.

Esquinas-Alcázar, J. 2005. Science and society: Protecting crop genetic diversity for food security: Political, ethical and technical challenges. Nat. Rev. Genet. 6:946-953.
Freeman, S., and Rodriguez, R. J. 1993. A rapid inoculation technique for assessing pathogenicity of Fusarium oxysporum $\mathrm{f}$. sp. niveum and F. o. melonis on cucurbits. Plant Dis. 77:1198-1201.

Goswami, R. S., and Kistler, H. C. 2004. Heading for disaster: Fusarium graminearum on cereal crops. Mol. Plant Pathol. 5:515-525.

Gottwald, S., Germeier, C. U., and Ruhmann, W. 2001. Computerized image analysis in Fusarium taxonomy. Mycol. Res. 105:206-214.

Gottwald, S., Samans, B., Lück, S., and Friedt, W. 2012. Jasmonate and ethylene dependent defence gene expression and suppression of fungal virulence factors: Two essential mechanisms of Fusarium head blight resistance in wheat? BMC Genomics 13:369.

Guenther, J. C., and Trail, F. 2005. The development and differentiation of Gibberella zeae (anamorph: Fusarium graminearum) during colonization of wheat. Mycologia 97:229-237.

Henkes, G. J., Jousset, A., Bonkowski, M., Thorpe, M. R., Scheu, S., Lanoue, A., Schurr, U., and Röse, U. S. 2011. Pseudomonas fluorescens CHA0 maintains carbon delivery to Fusarium graminearum-infected roots and prevents reduction in biomass of barley shoots through systemic interactions. J. Exp. Bot. 62:4337-4344.

Howard, R. J. 1997. Breaching the outer barriers-Cuticle and cell wall penetration. Pages 43-60. in: Plant Relationships. Carroll, G., and Tudzynski, P., eds. Springer, Berlin.

Jansen, C., von Wettstein, D., Schäfer, W., Kogel, K. H., Felk, A., and Maier, F. J. 2005. Infection patterns in barley and wheat spikes inoculated with wild-type and trichodiene synthase gene disrupted Fusarium graminearum. Proc. Natl. Acad. Sci. U.S.A. 102:16892-16897.

Kazan, K., Gardiner, D. M., and Manners, J. M. 2012. On the trail of a cereal killer: Recent advances in Fusarium graminearum pathogenomics and host resistance. Mol. Plant Pathol. 13:399-413.

Knudsen, I. M. B., Hockenhull, J., and Jensen, D. F. 1995. Biocontrol of seedling diseases of barley and wheat caused by Fusarium culmorum and Bipolaris sorokiniana: Effects of selected fungal antagonists on growth and yield components. Plant Pathol. 44:467-477.

Kravchenko, L. V., Shapozhnikov, A. I., Makarova, N. M., Azarova, T. S., L'vova, K. A., Kostyuk, I. I., Lyapunova, O. A., and Tikhonovich, I. A 2011. Exometabolites of bread wheat and tomato affecting the plantmicrobe interactions in the rhizosphere. Russ. J. Plant Physiol. 58:936-940.

Lannoo, N., Peumans, W. J., Pamel, E. V., Alvarez, R., Xiong, T. C., Hause, G., Mazars, C., and Van Damme, E. J. 2006. Localization and in vitro binding studies suggest that the cytoplasmic/nuclear tobacco lectin can interact in situ with high-mannose and complex N-glycans. FEBS Lett. 580:6329-6337.

Lanoue, A., Burlat, V., Henkes, G. J., Koch, I., Schurr, U., and Röse, U. S. R. 2010. De novo biosynthesis of defense root exudates in response to Fusarium attack in barley. New Phytol. 185:577-588.

Leplat, J., Friberg, H., Abid, M., and Steinberg, C. 2012. Survival of Fusarium graminearum, the causal agent of Fusarium head blight. A review. Agron. Sustain. Dev. 33:97-111.

Leslie, J. F., and Summerell, B. A. 2006. The Fusarium laboratory manual. Blackwell Publishing, Ames, Iowa.

Li, X., Zhang, J. B., Song, B., Li, H. P., Xu, H. Q., Qu, B., Dang, F. J., and Liao, Y. C. 2010. Resistance to Fusarium head blight and seedling blight in wheat is associated with activation of a cytochrome p450 gene. Phytopathology 100:183-191.

Looseley, M., and Newton, A. 2014. Assessing the consequences of microbial infection in field trials: Seen, unseen, beneficial, parasitic and pathogenic. Agronomy 4:302-321.

Maciá-Vicente, J. G., Jansson, H.-B., Talbot, N. J., and Lopez-Llorca, L. V. 2009. Real-time PCR quantification and live-cell imaging of endophytic colonization of barley (Hordeum vulgare) roots by Fusarium equiseti and Pochonia chlamydosporia. New Phytol. 182:213-228.

Magan, N., Medina, A., and Aldred, D. 2011. Possible climate-change effects on mycotoxin contamination of food crops pre- and postharvest. Plant Pathol. 60:150-163.

Marcel, S., Sawers, R., Oakeley, E., Angliker, H., and Paszkowski, U. 2010. Tissue-adapted invasion strategies of the rice blast fungus Magnaporthe oryzae. Plant Cell 22:3177-3187.

Martín-Rodrigues, N., Sanchez-Zabala, J., Salcedo, I., Majada, J., González-Murua, C., and Duñabeitia, M.K. 2015. New insights into radiata pine seedling root infection by Fusarium circinatum. Plant Pathol. doi: 10.1111/ppa.12376. Published online.

Mason, R. E., Mondal, S., Beecher, F. W., Pacheco, A., Jampala, B., Ibrahim, A. M. H., and Hays, D. B. 2010. QTL associated with heat susceptibility index in wheat (Triticum aestivum L.) under short-term reproductive stage heat stress. Euphytica 174:423-436.

Mudge, A. M., Dill-Macky, R., Dong, Y., Gardiner, D. M., White, R. G., and Manners, J. M. 2006. A role for the mycotoxin deoxynivalenol in stem colonisation during crown rot disease of wheat caused by Fusarium 
graminearum and Fusarium pseudograminearum. Physiol. Mol. Plant Pathol. 69:73-85.

Nicholson, P., Simpson, D. R., Weston, G., Rezanoor, H. N., Lees, A. K., Parry, D. W., and Joyce, D. 1998. Detection and quantification of Fusarium culmorum and Fusarium graminearum in cereals using PCR assays. Physiol. Mol. Plant Pathol. 53:17-37.

Paterson, R. R. M., and Lima, N. 2011. Further mycotoxin effects from climate change. Food Res. Int. 44:2555-2566.

Peraldi, A., Beccari, G., Steed, A., and Nicholson, P. 2011. Brachypodium distachyon: A new pathosystem to study Fusarium head blight and other Fusarium diseases of wheat. BMC Plant Biol. 11:100.

Percy, C. D., Wildermuth, G. B., and Sutherland, M. W. 2012. Symptom development proceeds at different rates in susceptible and partially resistant cereal seedlings infected with Fusarium pseudograminearum. Australas. Plant Pathol. 41:621-631.

Piccinni, G., Rush, C. M., Vaughn, K. M., and Lazar, M. D. 2000. Lack of relationship between susceptibility to common root rot and drought tolerance among several closely related wheat lines. Plant Dis. 84:25-28.

Pritsch, C., Muehlbauer, G. J., Bushnell, W. R., Somers, D. A., and Vance, C. P. 2000. Fungal development and induction of defense response genes during early infection of wheat spikes by Fusarium graminearum. Mol. Plant-Microbe Interact. 13:159-169.

Promputtha, I., Hyde, K. D., McKenzie, E. H. C., Peberdy, J. F., and Lumyong, S. 2010. Can leaf degrading enzymes provide evidence that endophytic fungi becoming saprobes? Fungal Divers. 41:89-99.

Puri, K. D., and Zhong, S. 2010. The 3ADON population of Fusarium graminearum found in North Dakota is more aggressive and produces a higher level of DON than the prevalent $15 \mathrm{ADON}$ population in spring wheat. Phytopathology 100:1007-1014.

Raaijmakers, J. M., Paulitz, T. C., Steinberg, C., Alabouvette, C., and MoënneLoccoz, Y. 2008. The rhizosphere: A playground and battlefield for soilborne pathogens and beneficial microorganisms. Plant Soil 321:341-361.

Ribichich, K. F., Lopez, S. E., and Vegetti, A. C. 2000. Histopathological spikelet changes produced by Fusarium graminearum in susceptible and resistant wheat cultivars. Plant Dis. 84:794-802.

Rittenour, W. R., and Harris, S. D. 2010. An in vitro method for the analysis of infection-related morphogenesis in Fusarium graminearum. Mol. Plant Pathol. 11:361-369.

Rocha, O., Ansari, K., and Doohan, F. M. 2005. Effects of trichothecene mycotoxins on eukaryotic cells: A review. Food Addit. Contam. 22:369-378.

Rodriguez, R. J., White, J. F., Jr., Arnold, A. E., and Redman, R. S. 2009. Fungal endophytes: Diversity and functional roles. New Phytol. 182: 314-330.

Rodriguez Estrada, A. E., Jonkers, W., Kistler, H. C., and May, G. 2012. Interactions between Fusarium verticillioides, Ustilago maydis, and Zea mays: An endophyte, a pathogen, and their shared plant host. Fungal Genet. Biol. 49:578-587.

Rowaished, A. K. 1981. The Influence of different forms of nitrogen on Fusarium root-rot disease of winter wheat seedlings. J. Phytopathol. 100: 331-339.

Ruan, Y. L. 2014. Sucrose metabolism: Gateway to diverse carbon use and sugar signaling. Annu. Rev. Plant Biol. 65:33-67.

Rudd, J. C., Horsley, R. D., McKendry, A. L., and Elias, E. M. 2001. Host plant resistance genes for Fusarium head blight. Crop Sci. 41:620-627.

Schneebeli, K., Mathesius, U., and Watt, M. 2015. Brachypodium distachyon is a pathosystem model for the study of the wheat disease rhizoctonia root rot. Plant Pathol. 64:91-100.

Schulz, B., and Boyle, C. 2005. The endophytic continuum. Mycol. Res. 109:661-686.

Sesma, A., and Osbourn, A. E. 2004. The rice leaf blast pathogen undergoes developmental processes typical of root-infecting fungi. Nature 431: 582-586.
Smiley, R. W., Gourlie, J. A., Easley, S. A., Patterson, L.-M., and Whittaker, R. G. 2005. Crop damage estimates for crown rot of wheat and barley in the Pacific northwest. Plant Dis. 89:595-604.

Smith, S., and De Smet, I. 2012. Root system architecture: Insights from Arabidopsis and cereal crops. Philos. Trans. R. Soc. Lond. B Biol. Sci. 367:1441-1452.

Sosnowski, M., Ramsey, M., Murray, G., Scott, E., and Wilmshurst, C. 2001. Symptoms of blackleg (Leptosphaeria maculans) on the roots of canola in Australia. Plant Pathol. 50:808.

Sukno, S. A., García, V. M., Shaw, B. D., and Thon, M. R. 2008. Root infection and systemic colonization of maize by Colletotrichum graminicola. Appl. Environ. Microbiol. 74:823-832.

Thatcher, L. F., Manners, J. M., and Kazan, K. 2009. Fusarium oxysporum hijacks COI1-mediated jasmonate signaling to promote disease development in Arabidopsis. Plant J. 58:927-939.

Trail, F. 2009. For blighted waves of grain: Fusarium graminearum in the postgenomics era. Plant Physiol. 149:103-110.

Trapero, C., Díez, C. M., Rallo, L., Barranco, D., and López-Escudero, F. J. 2013. Effective inoculation methods to screen for resistance to Verticillium wilt in olive. Sci. Hortic. (Amsterdam) 162:252-259.

Tucker, S. L., Besi, M. I., Galhano, R., Franceschetti, M., Goetz, S., Lenhert, S., Osbourn, A., and Sesma, A. 2010. Common genetic pathways regulate organ-specific infection-related development in the rice blast fungus. Plant Cell 22:953-972.

Tunali, B., Obanor, F., Erginbaş, G., Westecott, R. A., Nicol, J., and Chakraborty, S. 2012. Fitness of three Fusarium pathogens of wheat. FEMS (Fed. Eur. Microbiol. Soc.) Microbiol. Ecol. 81:596-609.

Vereijssen, J., Schneider, H. H. M., and Termorshuizen, A. J. 2004. Possible root infection of Cercospora beticola in sugar beet. Eur. J. Plant pathol. 110:103-106.

Vergne, E., Grand, X., Ballini, E., Chalvon, V., Saindrenan, P., Tharreau, D., Nottéghem, J. L., and Morel, J. B. 2010. Preformed expression of defense is a hallmark of partial resistance to rice blast fungal pathogen Magnaporthe oryzae. BMC Plant Biol. 10:206.

Walters, D. R., and Bingham, I. J. 2007. Influence of nutrition on disease development caused by fungal pathogens: Implications for plant disease control. Ann. Appl. Biol. 151:307-324.

Wang, H., Hwang, S. F., Eudes, F., Chang, K. F., Howard, R. J., and Turnbull, G. D. 2006. Trichothecenes and aggressiveness of Fusarium graminearum causing seedling blight and root rot in cereals. Plant Pathol. 55: 224-230.

Wanjiru, W. M., Kang, Z. S., and Buchenauer, H. 2002. Importance of cell wall degrading enzymes produced by Fusarium graminearum during infection of wheat heads. Eur. J. Plant Pathol. 108:803-810.

Weinhold, A., and Sinclair, J. 1996. Rhizoctonia solani: Penetration, colonization, and host response. Pages 163-174. in: Rhizoctonia Species: Taxonomy, Molecular Biology, Ecology, Pathology and Disease Control. S. Neate, and G. Dijst, eds. Springer Netherlands, Amsterdam.

Wu, A. B., Li, H. P., Zhao, C. S., and Liao, Y. C. 2005. Comparative pathogenicity of Fusarium graminearum isolates from China revealed by wheat coleoptile and floret inoculations. Mycopathologia 160: 75-83.

Xu, X., and Nicholson, P. 2009. Community ecology of fungal pathogens causing wheat head blight. Annu. Rev. Phytopathol. 47:83-103.

Zadoks, J. C., Chang, T. T., and Konzak, C. F. 1974. A decimal code for the growth stages of cereals. Weed Res. 14:415-421.

\section{AUTHOR-RECOMMENDED INTERNET RESOURCE}

Wheat Pedigree database: http://genbank.vurv.cz/wheat/pedigree 